\title{
Boreal summer sub-seasonal variability of the South Asian monsoon in the Met Office GloSea5 initialized coupled model
}

Article

Accepted Version

Jayakumar, A., Turner, A., Johnson, S., Rajagopal, E., Mohandas, S. and Mitra, A. (2017) Boreal summer subseasonal variability of the South Asian monsoon in the Met Office GloSea5 initialized coupled model. Climate Dynamics, 49 (5-6). pp. 2035-2059. ISSN 0930-7575 doi: https://doi.org/10.1007/s00382-016-3423-x Available at https://centaur.reading.ac.uk/66554/

It is advisable to refer to the publisher's version if you intend to cite from the work. See Guidance on citing.

To link to this article DOI: http://dx.doi.org/10.1007/s00382-016-3423-x

Publisher: Springer

All outputs in CentAUR are protected by Intellectual Property Rights law, including copyright law. Copyright and IPR is retained by the creators or other copyright holders. Terms and conditions for use of this material are defined in the End User Agreement. 


\section{CentAUR}

Central Archive at the University of Reading

Reading's research outputs online 
1 Boreal summer sub-seasonal variability of the South Asian monsoon in the Met Office

2 GloSea5 initialized coupled model

3

4

A. Jayakumar, A.G. Turner, S.J. Johnson, E.N. Rajagopal, Saji Mohandas and A.K.Mitra

5

6

7

8

9

10

Submitted to Climate Dynamics Dec, 17, 2015

11

12

13

14

15

16

17

18

19

20

A. Jayakumar

NCMRWF, MOES

Noida, India

22

Email: jkumarencmrwf.gov.in

24 
Abstract Boreal summer sub-seasonal variability in the Asian monsoon, otherwise known as the monsoon intra-seasonal oscillation (MISO), is one of the dominant modes of intraseasonal variability in the tropics, with large impacts on total monsoon rainfall and India's agricultural production. However, our understanding of the mechanisms involved in MISO is incomplete and its simulation in various numerical models is often flawed. In this study, we focus on the objective evaluation of the fidelity of MISO simulation in the Met Office Global Seasonal forecast system version 5 (GloSea5), an initialized coupled model. We analyze a series of ninemember hindcasts from GloSea5 over 1996-2009 during the peak monsoon period (July-August) over the South-Asian monsoon domain focusing on aspects of the time-mean background state and air-sea interaction processes pertinent to MISO. Dominant modes during this period are evident in power spectrum analysis, but propagation and evolution characteristics of the MISO are not realistic. We find that simulated air-sea interactions in the central Indian Ocean are not supportive of MISO initiation in that region, likely a result of the low surface wind variance there. As a consequence, the expected near-quadrature phase relationship between SST and convection is not represented properly over the central equatorial Indian Ocean, and northward propagation from the equator is poorly simulated. This may reinforce the equatorial rainfall mean state bias in GloSea5.

Keywords monsoon intra-seasonal oscillation; Met Office Global seasonal forecast; SST

\section{Introduction}

The Indian monsoon is one of the most energetic components of the South Asian climate system, acting as a large source of diabatic heating over the tropical belt. Within its strong seasonality, there are prolonged spells of wet and dry conditions lasting for 2-3 weeks, with profound socioeconomic implications particularly in the agricultural sector. These periods, known as active and break conditions respectively, represent the extreme phases of sub-seasonal or monsoon intraseasonal oscillations (MISO; e.g., Sikka and Gadgil 1980; Srinivasan et al. 1993; Goswami 2011). With useful prediction skill of monsoon subseasonal variability currently extending to only around two weeks (Abhilash et al. 2014), improvement in the simulation and forecasting of these modes is a key goal for the research community and is reflected as a main objective of the National Monsoon Mission established by the Government of India. 
54 Active and break events are generally found in observations with a periodicity of 30-60 days 55 (e.g. Annamalai and Slingo 2001). Large coherent variability is displayed in different 56 atmospheric and upper-ocean fields in accord with monsoon active-break cycles. During active 57 phases, there is a strengthening of the monsoon jet, and increased convection over the Indian 58 mainland, eastern Arabian Sea and the Bay of Bengal, whereas during the break phase, there is increased convection over the eastern equatorial Indian Ocean, and the low-level jet is deflected to the south, resulting in decreased wind over the aforementioned regions (Webster et al. 1998; 61 Annamalai and Slingo 2001; Joseph and Sijikumar 2004). The regional Hadley circulation 62 moves northward, bringing anomalous ascending (descending) air together with cyclonic (anti63 cyclonic) low-level circulation anomalies over India for the active (break) phases, which 64 ultimately modulate the mean monsoon flow itself. Thus strong ocean-atmosphere air-sea 65 interaction is clearly exhibited in SST, convection and low-level wind fields over the tropical Indian Ocean corresponding to active-break cycle (Joseph and Sabin 2008).

MISO convective activity is coupled with the upper ocean through SST and wind stress. In turn, SST feeds back on the atmosphere through surface moisture convergence and changes in the stability of the planetary boundary layer (Roxy and Tanimoto 2007). SST cooling (warming) over the Bay of Bengal and east Arabian Sea are followed by the movement of the monsoon jet and convection into the region for respective active (break) phases. Weak winds over a wellstratified low-salinity layer in the north Bay of Bengal result in a shallow mixed layer, which responds rapidly to perturbations in net heat flux at the surface arising from MISO; this is indicative of strong coupling. Using in-situ observations and satellite images, Sengupta et al. (2001) and Fu et al. (2003) attributed most of the SST changes on MISO time scales in this area to fluctuations in net heat flux. Three-dimensional (3D) fully dynamic ocean models have also confirmed the dominant role of heat flux over other oceanic processes in controlling SST variability in the Bay of Bengal (Vialard et al. 2011).

The prediction skill of interannual monsoon variability has been improved by using fully coupled models rather than forced atmospheric models (Kumar et al. 2005), since the former includes ocean-atmosphere interaction; this can be clearly inferred from the SST-precipitation relationship exhibited in Wang et al. (2005). Similarly at the intraseasonal time scale, Rajendran et al. (2004) 
demonstrated the essential role of air-sea interaction processes in achieving the proper amplitude and phase of MISO in the coupled models in IPCC AR4. Sperber and Annamalai (2008) analysed the CMIP3 models and suggested that the fidelity of the un-initialized coupled model representation of MISO is better in those models that feature the necessary background conditions for the proper life cycle and the northward propagation of MISO. They identify these conditions as: realistic location of the time-mean monsoon heat sources (both in precipitation and SST), with easterly wind shear in the vertical and a meridional gradient of specific humidity.

In the present study, we evaluate the simulation of MISO in the UK Met Office Global Seasonal forecast system version 5 GC2 (hereafter referred to as GloSea5; Williams et al. 2015) over the Indian monsoon domain, and the underlying air-sea interaction processes involved. No previous work has studied the fidelity of MISO in GloSea5. This study deals with the nature of activebreak cycles in GloSea5 and diagnoses the possible sources of error in precipitation and lowlevel wind over the monsoon domain using a nine-member hindcast for the 14-year period of 1996-2009 in comparison to reanalysis/satellite products. Our assessment of active-break cycles will test the previously mentioned background conditions before examining precipitation-SST relationships and the air-sea interaction processes involved in it. Section 2 describes the observational data sets used, along with the methodology for defining active and break events and model details. The large-scale time-mean background state is examined in Section 3. Section 4 addresses the dominant periodicity simulated in the model at intraseasonal time scales and associated propagation characteristics, while the spatial horizontal and vertical patterns of MISO are described in Section 5. Air-sea interaction processes associated with MISO are presented in Section 6 and finally Section 7 summarizes the results with further discussion.

\section{Model and observations used}

\subsection{Observations}

We used daily TRMM satellite rainfall based on the $3 \mathrm{~b} 42$ algorithm (Huffman et al. 2007) as our observed precipitation, covering the period 1998-2013. For dynamic and thermodynamic atmospheric fields on pressure levels (winds, temperature, humidity and vertical motion), we used the ECMWF ERA-Interim reanalysis (Dee et al. 2011; hereafter ERA-Interim). TMI SST 
111 (Wentz et al. 2000) and 10m winds from the daily gridded QuikSCAT scatterometer (Bentamy et 112 al. 2003) have been used for additional model verification at the surface. For oceanic surface 113 fluxes, since observations are so uncertain in the Indian Ocean, model outputs have been

114 validated against two independent flux products including the objectively analysed flux from the

115 Woods Hole Oceanographic Institute (WHOI OAFlux; Yu and Weller 2007) and TropFlux 116 (Praveen Kumar et al. 2011). The July-August mixed layer depth (MLD) climatology is taken 117 from a data set presented in de Boyer Montégut et al. (2004). All these observation and 118 reanalysis data are used over the common period of 1998-2013.

119

120

121

122

123

124

125

126

127

128

129

130

131

132

133

134

135

136

137

138

139

\subsection{Model details}

Williams et al. (2015) describe the GloSea5 Global Coupled model 2.0 (GC2) system, which is an initialized version of the recent high-resolution Hadley Centre Global Environment Model version 3 (HadGEM3) atmosphere-ocean coupled climate model. The following are the main components in this seasonal forecast system: Met Office Unified Model (MetUM) atmosphere GA6.0 (Walters et al. 2015) with the latest dynamical core (Even Newer Dynamics for General Atmospheric Modelling of the Environment, ENDGame; Wood et al. 2014), the Joint UK Land Environment Simulator GL6.0 (JULES; Best et al., 2011, Walters et al. 2015) land model, the Nucleus for European Modelling of the Ocean GO5 (NEMO; Madec 2008, Megann et al. 2014) ocean component, and the Los Alamos sea-ice model GSI6.0 (CICE; Hunke and Lipscomb 2010, Rae et al. 2015). GloSea5 uses $\mathrm{N} 216$ horizontal resolution $\left(0.8^{\circ}\right.$ in latitude and $0.5^{\circ}$ in longitude) for the atmosphere, and $0.25^{\circ}$ for the ocean (Williams et al. 2015, MacLachlan et al. 2015). The vertical resolution is 85 levels for the atmosphere, giving a well-resolved stratosphere, and 75 levels for the ocean.

To assess the behaviour of the seasonal forecast system over an extended period, a hindcast set is used over a range of years. The GloSea5 hindcast period covers 1996-2009, which for the summer season (as in this case) is initialised at start dates of April 25, May 5 and May 9. MetUM and JULES are initialized from ERA-Interim (Dee et al. 2011) and NEMO and CICE are initialized from GloSea5 Ocean and Sea ice analysis, but soil moisture is initialized with interannual variation from a JULES reanalysis. Further details of the initialization and data assimilation scheme are given in MacLachlan et al. 2015 and Johnson et al. 2016. Each start-date 
has three ensemble members and is integrated for 140 days, extending beyond the end of August. Spread between the ensemble members is created by the SKEB2 stochastic physics scheme (Bowler et al. 2009). These hindcast data from the nine total samples for each year are used in the current study. Xavier et al. (2014) used a previous version of the Met Office seasonal forecast system (GloSea5-GA3). They showed high skill in simulation of the Madden Julian Oscillation in winter and analyzed the general tropical performance in extreme rainfall cases.

\subsection{Identification of active-break events}

Identification of active-break events is based on daily rainfall averaged over the monsoon core zone (MCZ), as shown in Figure 4a of Rajeevan et al. (2010). Standardized rainfall is first calculated by removing the climatological seasonal cycle and then dividing it by the normalized daily value for the seasonal cycle. A break (active) spell is identified as a period during which the standardized rainfall anomaly is less (more) than -1.0 (+1.0) for three consecutive days or more. We define the time of lag-0 corresponding to the peak rainfall phase of an event. Lagged composites of all variables of interest are made with reference to active (break) rain events in the MCZ. Table 1 lists active-break events based on the aforementioned criteria using TRMM and these spells are well compared with the spells identified in Rajeevan et al. (2010) using Indian Meteorological Department (IMD) data sets. Over the MCZ, intraseasonal variability using TRMM is highly correlated with IMD rain-gauge data (Figure 1 of Jayakumar et al., 2013) and sub-seasonal variability of TRMM over both land and ocean is good during the monsoon period (Rahman et al. 2009). In addition to the 'active-break events decomposition' method described here, we also isolate the 30-60 day MISO signal by applying a Lanczos filter (Duchon 1979) on daily anomaly data with 121 weights.

For the model 'active-break events decomposition', we have used normalized model rain anomaly calculated using 14 years of GloSea5 hindcast climatology covering the period from 1996 to 2009 and calculated separately for each member of the ensemble to obtain thresholds for defining active/break dates. Since most MISO activity takes place within July-August months (Rajeevan et al. 2010; Jayakumar et al. 2013), to avoid signals from the onset and withdrawal of the monsoon, and to maintain a sufficient distance from the initialization dates, the diagnostics to be presented here are for July and August. The average number of events identified per ensemble 
169

170

171

172

173

174

175

176

177

178

member was around 27 for active and 15 for break events respectively (i.e. the total number of events identified divided by nine ensemble members) in GloSea5 14 year hindcast (Table 1), while 34 active and 35 break events were identified in the 16 years of TRMM data. To ensure robustness in the results, we concatenate all events from each member having three initial conditions, so that we have a large sample of events. We remind the reader that GloSea5 is not be expected to simulate equivalent (in phase) active or break events during July-August to those in observations since initialization occurs too far in advance. However, performing an analysis of the average fidelity of active-break events in the seasonal hindcast framework allows us to examine them in an initialized coupled model system in which mean-state SST errors are as small as possible.

\section{The large-scale time-mean environment}

As discussed in Section 1, realistic locations of time-mean monsoon heat sources and the easterly wind shear in the vertical are necessary conditions for a model to simulate the proper amplitude and phase of MISO. Figure 1a shows July and August mean monsoon precipitation in TRMM and the GloSea5 ensemble mean. There is a primary maximum over the monsoon trough region (between $10^{\circ} \mathrm{N}$ and $25^{\circ} \mathrm{N}$ ) and into the Bay of Bengal, and a secondary maximum over the oceanic tropical convergence zone of the East Equatorial Indian Ocean (EEIO). While GloSea5 reasonably simulates the pattern of precipitation in the northern region including the monsoon trough location, there is not enough rainfall in the EEIO secondary maximum. The SST maximum between the equator and $10^{\circ} \mathrm{S}$ marks the preferred location for the secondary precipitation maximum, yet in GloSea5 the SST maximum is slightly too far north and too cold by around $1{ }^{\circ} \mathrm{C}$ (Fig. $\left.1 \mathrm{~d}, \mathrm{e}\right)$. Both locations are associated with low-level cyclonic vorticity and represent two preferred locations of the tropical convergence zone (e.g. Turner and Hannachi 2010). These two regions play an important role in spatial variations associated with the activebreak cycle and its northward propagation. Compared to the uninitialized atmosphere-only version of this model (HadGEM3 GA6.0), the mean precipitation bias in GloSea5 is, as expected, much reduced over the Indian land surface and over the equator, which bodes well for the assessment of subseasonal variability in this framework. The July-August mean SST bias shows characteristic cold SSTs (by more than $\sim 1.2^{\circ} \mathrm{C}$ ) in the equatorial region and Bay of Bengal 
and positive SST biases in the western Arabian Sea. The spatial shift of this equatorial SST maximum to the north of the observational position and penetration further east of the equatorial cold tongue is a long-standing bias in coupled versions of the Met Office Unified Model (e.g. Johnson et al. 2016) and may be a manifestation of an enhanced coupled Bjerknes feedback over the Indian Ocean, resulting in convergence and convection being shifted further northwestward (Fig. 1c and 1f). A westerly wind bias can be seen in the lower troposphere ( $850 \mathrm{hPa})$ across the Indian mainland between $5^{\circ} \mathrm{N}$ and $25^{\circ} \mathrm{N}$, whereas an easterly wind bias is seen over the EEIO close to Indonesia and the Sumatra region (Fig. 1c), consistent with the SST bias and exaggerated cold tongue. The southeasterly wind bias in the equatorial region acts to reduce the SST there through wind-evaporation feedbacks and enhanced coastal and equatorial upwelling as in the Bjerknes feedback. Alternatively, pressure perturbations produced by deep convection and sea surface temperature (SST) gradients may play a role in the westerly wind bias over the Indian mainland and easterly bias over the EEIO.

The overall bias of monsoon precipitation in the GloSea5 model is small when compared to the overall large dry bias seen in uninitialized coupled models of CMIP5 (Sperber et al. 2013). This is likely due in part to the proximal initialization in late spring and therefore the absence of significant cold bias errors in the Arabian Sea (Marathayil et al. 2013; Levine et al. 2013), which are known to lead to reduction in rainfall in the summer monsoon of coupled models. However, GloSea5 still suffers from excessive precipitation in the western equatorial Indian Ocean.

Jiang et al. (2004) proposed the importance of vertical wind shear and the meridional gradient of surface humidity in the northward propagation of MISO. They showed that the vertical easterly wind shear strengthened low-level convergence ahead (north) of the convection through barotropic vorticity generation there. Hence the ability of a model to simulate spatial variations of vertical wind shear and specific humidity is a necessary condition for the northward propagation characteristic of MISO in a coupled model (e.g. Sperber and Annamalai 2008). Figure 2 shows that July-August mean easterly vertical wind shear in the model is particularly strong in the northern Indian Ocean with a maximum located over the western Arabian Sea, particularly in the axis region of the climatological low-level Somali jet. But in the case of the near-surface $(10 \mathrm{~m})$ specific humidity, the model consistently simulates values that are too low all 
227 the way from south to north of the Indian Ocean. The stronger vertical wind shear may 228 compensate for the low basin-mean humidity, allowing a reasonable simulation of northward propagation of MISO in the model. However, as we shall see, mere representation of the timemean basic state alone does not guarantee a realistic simulation of the MISO.

231

The July-August climatology of the monsoon local Hadley circulation and vertical pressure velocity from ERA-Interim and GloSea5 is illustrated in Fig. 3a and 3b. The meridional vertical distribution of the local Hadley circulation shows an ascending branch with maximum strength at around $20^{\circ} \mathrm{N}$ and a corresponding descending motion south of $10^{\circ} \mathrm{S}$ in ERA-Interim (Fig. 3a). The local Hadley circulation in GloSea5 displays a stronger ascending motion at $20^{\circ} \mathrm{N}$ and just north of the equator, leading to an elongated circulation in GloSea5 (Fig. 3c). The strong monsoon westerlies with their core around $850 \mathrm{hPa}$ and maximum at $15^{\circ} \mathrm{N}$ can be seen in the seasonal zonal wind from both observations and GloSea5 (Fig. 3d). The prevailing westerly winds in the northern hemisphere summer extend up to $400 \mathrm{hPa}$ height with a southward tilt. As seen in Figure 1, low-level westerly winds in the northern hemisphere are slightly stronger in GloSea5 (up to $800 \mathrm{hPa}$ ). As we shall see in the next section, these mean state biases of the local climate also project onto active-break events in GloSea5.

\section{Power spectra and wave-number frequency spectra of observed and GloSea5 intraseasonal variability}

Before diagnosing the characteristics of the model monsoon active-break cycle, we use power spectra for estimating the dominant periodicity simulated in the model at intraseasonal time scales with respect to the available observations. In general, significant periodicities in both U850 and OLR power spectra from the model and ERA-Interim are in good agreement. However, power retained in the 30-60 day band in the model is weaker than in ERA-Interim (Fig. 4). The amplitude of the higher frequency band below 20 day period is found to be stronger in the model.

Both eastward and northward propagating components are evident in intraseasonal oscillations during the monsoon period (e.g., Kemball-Cook and Wang 2001). To examine this behaviour in GloSea5 we have computed east-west and north-south space-time spectra following the 
methodology of Wheeler and Kiladis (1999). Figure 5a shows the dominant power in the northward propagating component at wavenumber 1 from observations calculated over the Indian monsoon domain, which is consistent with results of earlier studies during boreal summer (e.g. Goswami 2011). The GloSea5 model shows a slightly weaker northward propagating component, but the southward-propagating component is overestimated in the negative axis of the wavenumber (Fig. 5b). In accordance with the high frequency variability seen in the power spectra, the southward propagating component here is shifted slightly toward the shorter time scales. In contrast to eastward propagating signals of the Madden-Julian Oscillation (MJO, Zhang 2005) with maximum power at wavenumber 1-3 evident in the observed east-west wave spectra during winter (Fig. 5c), the GloSea5 model shows less power distributed over a larger range of wavenumbers (Fig. 5d). Overestimated power at longer than observed MJO time scale is simulated in both eastward and westward propagation, which is unrealistic. The westward Rossby wave response to the eastward-moving MJO is much amplified in the model at periods longer than 80 days. The mean cold bias in the EEIO (Fig. 1) could be largely caused by the lack of strong enough boreal-summer MJO activity over the equatorial Indian Ocean. The weaker MJO activity during boreal summer and its relation to the mean cold SST bias is beyond the scope of the current work, since our focus is on the ability of GloSea5 to simulate the MISO.

\section{Characteristics of the GloSea5 monsoon active-break cycle}

In this section we analyse the spatial pattern and vertical structure of a composite active-break cycle in GloSea5 based on the Rajeevan et al. (2010) rainfall index described in section 2.3

\subsection{Spatial pattern}

We have used a time-lagged composite analysis of low-level winds and precipitation to derive the spatiotemporal evolution of the monsoon active-break cycle. This lagged composite analysis will also help us gain an idea of the evolution of active-break events in the observations and the GloSea5 model. Evolution of the TRMM and GloSea5 rainfall active and break events and associated low-level wind anomalies from ERA-Interim and GloSea5 is displayed using composite lags ranging from -12 to +12 days and shown in Fig. 6a,b and Fig. 6c,d respectively. Lag $=0$ denotes the peak phase of active and break event composites, the respective figure panels 
283

284

285

286

287

288

289

290

291

292

293

294

295

296

297

298

299

300

301

302

303

304

305

306

307

308

309

310

showing positive rainfall anomalies over the MCZ and north Bay of Bengal (Fig. 6a) and equatorial Indian Ocean (Fig. 6b) respectively; these patterns are consistent with those discussed in previous studies (e.g. Annamalai and Slingo 2001; Rajeevan et al. 2010). For GloSea5 lag=0, a similar pattern is generated for the Indian mainland, but the amplitude of the rainfall anomaly over the Bay of Bengal is reduced compared to observations. Thus while our observational and model composites are selected using the same MCZ method over land, GloSea5 shows a much weaker connection with anomalies of the same sign over the north Bay of Bengal. The largest errors in the anomaly composites when compared to observations are over the EEIO, especially during the break phase (Fig. 6d). This suggests that GloSea5 faces problems in simulating the connection between anomalies in the continental tropical convergence zone and the oceanic tropical convergence zone. ERA-Interim low-level wind anomalies associated with the composite active-break cycle are characterized by two vortices of opposite sign in the circulation field, close to the equator, similar in structure to the $n=2$ equatorial Rossby wave (Krishnan et al. 2000). This pattern is visible in both GloSea5 with only small differences relative to ERAInterim. From twelve days before (lag=-12) to three days (lag=-3) before the peak of the observed active spell, positive rainfall anomalies weaken in the eastern Arabian Sea while they intensify in the Bay of Bengal (Fig. 6a). By lag=0, rainfall anomalies extend to the MCZ from the Bay of Bengal, and a corresponding shift in the axis of the low-level jet is found in the wind anomaly. After the peak phase (lag=+3), the positive rainfall anomaly bifurcates to two bands of rainfall along north-west India and in the eastern portion of the north Bay of Bengal. Similar patterns characterize the break during phases closes to the event peak (lag=0) with negative rainfall anomalies over the MCZ and Bay of Bengal and positive rainfall anomalies along the Himalayan foothills and equatorial Indian Ocean (Fig. 6b). But the asymmetric nature in rainfall patterns and associated circulation patterns between active and break composites during the evolution (lag=-12 to lag=-6) and dissipation (lag=+6 to lag=+12) of the events is clearly depicted in Fig. 6a and Fig. 6b respectively. Though the GloSea5 spatial pattern is largely consistent with observations during the phases close to the peak spell of active/break events, greater inconsistencies can be seen away from the peak spells (Fig. 6c and Fig. 6d). 
313 We now examine the vertical structures of the local monsoon Hadley circulation and zonal winds 314 associated with active and break phases over the Indian Ocean region. During active periods, strong anomalous ascending motion is found over the north Bay of Bengal with respect to 316 climatology as shown in Fig. 7a. This motion is associated with deep convection in the monsoon 317 trough region, whereas weakening of the local Hadley circulation is found during break periods 318 (Fig. 7b). Differences in the heating and meridional transport between active and break events is 319 clearly visible in the ERA-Interim active-break cycle. In GloSea5 (Fig. 3c), biases can also be 320 seen for active and break periods (Fig. 7c,d). During break events, the anomalous circulation is 321 more meridionally confined compared to ERA-Interim, with particularly weak anomalies over 322 the equator (Fig. 7d). The anomalous descending motion in GloSea5 active periods is also weak 323 and meridionally confined (Fig. 7c).

324 The vertical structure of zonal wind anomalies for both ERA-Interim and GloSea5 is illustrated 325 in Fig 8. Enhanced westerly winds associated with active convection over the monsoon trough 326 region appear to be barotropic in nature north of $10^{\circ} \mathrm{N}$, and are clearly visible in both ERA327 Interim (Fig. 8a,b) and GloSea5 (Fig. 8c,d). Similarly, reduced westerly winds associated with 328 break conditions are well represented in GloSea5. In the GloSea5 break phase, an anomalous 329 westerly tongue south of the equator extends as far as $20^{\circ} \mathrm{S}$, from $200 \mathrm{hPa}$ down to the midtroposphere, quite different from the narrow extent of this feature in ERA-Interim. Similarly, anomalous upper-level easterly winds extend too far south in the active phase. One possible reason for the erroneous upper-level vertical wind anomalies during the break phase may be the unrealistic vertical distribution of heat fluxes relating to deficiencies in the parametrization of 334 deep convection, which are beyond the scope of this study. Model-simulated wind anomalies 335 during both active and break periods are very weak below $800 \mathrm{hPa}$ in the equatorial Indian Ocean 336 region.

337 There are thus clear biases in the horizontal and vertical structure of composite active and break 338 events in GloSea5. The next section will explore air-sea interaction processes relating to these 339 biases. 


\section{Air-sea interaction process associated with GloSea5 MISO}

MISO can be modified by air-sea interaction processes that modulate the propagation and life cycle of active-break convective activity. This section mainly addresses air-sea interaction process using available observational data sets and GloSea5.

\subsection{Regression and correlation analysis}

Lag-latitude diagrams of 30-60 day filtered precipitation (shaded) and SST (contour) regressed onto reference time series over the Bay of Bengal $(\mathrm{BoB})$ and the central/east equatorial region (Eq) are shown in Fig. 9a-d. Here the Eq region is same as EEIO used earlier (Figure 1), except the longitudinal range is extended to $70^{\circ} \mathrm{E}$ instead of $85^{\circ} \mathrm{E}$ to also cover the central Indian Ocean signal. In observations (Fig. 9a,c), there is a clear northward propagation of MISO apparent both at Bay of Bengal and equatorial latitudes in precipitation and SST anomalies. This northward propagation is associated with cyclonic vorticity ahead of the convection in the background monsoon flow and an easterly wind shear in the vertical (Goswami 2011). Air-sea coupling is certainly a feature of the northward propagation of MISO given the strong quadrature relationship ( $\sim 0^{\circ}$ phase lag) between precipitation and SST. The $90^{\circ}$ phase relationship can be seen clearly in the observations, with warm SST leading the positive phase of the convective anomaly, and vice-versa. However, in GloSea5 (bottom row), propagation is not clear in precipitation or SST and the $\sim 90^{\circ}$ phase lag relationship is not maintained properly especially in the equatorial region (Fig. 9d). This can be better elucidated by considering the lead-lag correlation of filtered anomalies of rainfall averaged over box-averaged regions over the head of the Bay of Bengal and equatorial regions (Fig. 9e). This correlation diagram represents the strength of the correlation in the quadrature relationship between SST and precipitation. In observations, SST anomaly correlations peak 10-15 days ahead of the precipitation anomaly. Over the north Bay of Bengal (see black curves in Fig. 9e), this relationship is captured in the model, but is weaker than in the observations. Over equatorial latitudes (red curves) there is an extremely weak correlation between these fields in GloSea5, and the phase of the relationship is also incorrect, with SSTs being most highly anti-correlated with current precipitation, rather than lagged precipitation. 
To quantify the role of air-sea interactions in GloSea5 in more detail, we perform a detailed analysis of air-sea flux, SST and precipitation, specifically focused on the BoB and Eq regions. The net air-sea flux at the sea surface is given by the sum of net radiative fluxes (longwave and shortwave radiation) and turbulent fluxes (latent and sensible heat fluxes). Changes in the circulation and precipitation will have an impact on the net heat flux $\left(Q_{\text {net }}\right)$ perturbation. A quadrature phase relationship also exists between SST and $\mathrm{Q}_{\text {net, }}$ indicating that intraseasonal SST fluctuations are essentially being driven by the atmosphere through $\mathrm{Q}_{\text {net }}$ as in previous studies by Sengupta et al. (2011) and Vialard et al. (2011). Figure 10 shows the lag regression analysis of 30-60 day filtered $\mathrm{Q}_{\text {net }}$ and its components (shortwave, latent heat, longwave and sensible heat) onto the 30-60 day filtered SST in the BoB and Eq from OAFlux and GloSea5. The OAFlux observed estimate shows the dominant contribution of short wave flux variations to the total net heat flux perturbation, which is consistent with earlier work by Vialard et al. (2011). The amplitude and phase of the GloSea5 net heat flux and its components shows a similar pattern in BoB consistent with OAFlux, although latent heat variations are slightly overestimated and the SW flux variations are underestimated, resulting in an overall underestimation of the net heat flux variations. In the equatorial box, GloSea5 shows poor performance in simulating the amplitude of net heat flux and its components, with verylow values of all terms. Additionally we have calculated lead-lag correlations for precipitation against atmospheric fields (figure not shown) such as OLR, net surface flux, SW flux, LHF and wind speed (WS) for +20 day to -20 day lags following a similar method to that presented in Fig. 9e. Cloud-precipitation relationships are found to perform well over the GloSea5 equatorial region, although further discussion on convection parametrization is not within scope of the current work. Clear phase mismatches are reflected in the latent heat flux and wind speed correlation analysis, along with SST-precipitation presented earlier (Fig. 9e). This suggests that a deeper analysis of sources of bias in the LH flux is significant. The next section focuses on the decomposition of drivers of latent heat flux variations rather than the short wave flux, since latent heat flux part is partially related to the variations of primary fields in the model such as low-level wind, humidity and SST and there are clear biases in those fields in the model, particularly near the equator. 


\subsection{Latent heat flux decomposition}

Latent heat flux $(L)$ is calculated using the bulk aerodynamic formula of the form:

$$
L H=\rho C C_{e} L W\left[Q_{s}-Q_{a}\right]
$$

where $\rho$ is the air density, $L$ is the latent heat of evaporation, $C_{e}$ is a transfer coefficient, $W$ is the near-surface wind speed, $Q_{S}$ is the near-surface specific humidity and $Q_{a}$ is the specific humidity at $2 \mathrm{~m}$ above surface. $Q_{S}(T)$ is the saturation specific humidity at the ocean surface calculated using the Clausius-Clapeyron relation. We linearize latent heat flux at the daily time scale by adding a residual (error) term to the contributing terms from SST, wind and surface humidity. This linearization can be written as:

$$
L H=\overline{L H}+\underbrace{\overline{L H} \mid \frac{W^{\prime}}{\bar{W}}}_{\text {wind }}+\underbrace{\overline{L H}\left(\frac{Q_{s}^{\prime}}{\overline{Q_{s}}-\overline{Q_{a}}}\right)}_{\text {SST }}+\overline{L H} \underbrace{\left(\frac{Q^{\prime} a}{\overline{Q_{s}}-\overline{Q_{a}}}\right)}_{\text {Hunidity }}+\underbrace{\varepsilon}_{\text {error }}
$$

407 , where the overbar and prime symbols denote the daily mean and perturbation values, 408 respectively. The contribution from the error term $(\varepsilon)$ is not significant in the observational 409 decomposition using OAFlux, though the error has a slightly higher value in the model. We have also verified the observational latent heat flux decomposition with TropFlux (Praveen Kumar et al. 2011), which is independent of OAFlux, with consistent results (Figure not shown). The LH decomposition terms are shown for both observations and GloSea5 in Fig. 11. Total LH

413 flux variability from observations shows maxima over the BoB and equatorial region (Fig. 11a), 414 whereas GloSea5 shows a maximum over the western Arabian Sea (Fig. 11f). In general, $L H$ decomposition terms show spatial coherence in accordance with the variability of $L H$ as a whole 416 (Fig. 11 a-e). In GloSea5, there is an over-estimation of the contribution of SST variability to $L H$ 417 flux variability in the western Arabian Sea as well as off Sumatra (Fig. 11g). The warm bias of 418 the model SST in the western Arabian Sea (Fig. 1f) may be a causative factor of the anomalous contribution of SST variability to LH flux changes in this region. Wind has the largest 
contribution to the total observed LH flux variability (Fig. 11a,d). Lack of variance in the equatorial wind (Fig. 13c) contributes to the low $L H$ variability in the EEIO in GloSea5 (Fig. 11i), which is a prominent feature in OAFlux for this region (Fig. 11d). Instead of in the EEIO, the GloSea5 model shows maximum variance of wind-contributed LH variability in the southeast Arabian Sea (Fig. 11i), where the variability from $\varepsilon$ also shows slighter higher values compared to OAFlux.

\subsection{Impact of net heat flux variations on a thermodynamic slab ocean}

To calculate the potential change in SST associated with fluctuations in the net surface heat flux, we approximate a simple ocean using a slab-ocean mixed layer depth approach as, $\frac{d T}{d t}=\left(\frac{Q_{0}}{\rho c_{p} h}\right)$, where $Q_{o}$ and $h$ are the net heat flux perturbation and July-August climatological mixed layer depth (MLD) respectively. We obtain the observed climatological MLD from the de Boyer Montégut data set (de Boyer Montégut et al. 2004). The net heat flux variations are 30-60 day bandpass filtered for the observations and model at each grid point, and used to force the slab model. The 30-60 day SST variability obtained from the slab ocean approach in GloSea5 is missing its equatorial maximum (Fig. 12), consistent with the earlier analysis. Intraseasonal SST variability in the equatorial Indian Ocean region has an important role in the mechanism of the northward propagation of MISO through changes in the net heat flux and SST, which eventually brings about convective changes here through destabilizing the lower atmosphere and enhancing moist static energy as discussed in previous literature (e.g. Roxy and Tanimoto 2007). In case the model MLD should be biased, for the model we have also repeated the slab-ocean approach, using observed MLD instead of GloSea5 MLD, which resulted in similar SST variance (figure not shown); this suggests that it is biases in the intraseasonal surface heat flux perturbation rather than mean state model MLD biases that are damping the intraseasonal variability of SST in the GloSea5 equatorial region. The July-August slab-ocean SST response in GloSea5 is therefore not supporting the coherent quadrature phase relationship between SST and precipitation, which may thus have an impact on the spatial structure of MISO and its northward propagation. 


\section{Summary and discussion}

\subsection{Summary}

451 We have carried out an assessment of sub-seasonal variability using a 9-member 14-year set of 452 coupled hindcasts in the GloSea5 initialized seasonal forecast model during boreal summer by 453 examining the time-mean background state, and the spatial pattern and vertical structure of the active-break cycle of monsoon intraseasonal oscillations based on a rainfall index over the monsoon core zone. The main features of the simulated time-mean background state are the overly strong low-level jet (westerly wind bias), a warm SST bias over the western Arabian Sea with respect to observations, together with a coupled wind and SST bias in the equatorial Indian Ocean with excessive trade winds and cold SSTs.

Dominant modes of monsoon intraseasonal oscillation are clearly displayed in apower spectrum analysis, but the strength of the 30-60 day (10-20 day) mode is under (over) estimated. East-west and north-south space-time spectra during this season show weak MJO and northward 462 propagating components at wavenumber 1.

463 The spatial pattern of the precipitation and low-level wind anomalies in the lagged-composite of 464 active and break events over the Indian mainland and north Bay of Bengal are in reasonable 465 agreement with observations, whereas large deviations from observations are noted over the

467 Hadley circulation and vertical profile of zonal wind are in reasonable agreement with respect to 468 ERA-Interim reanalysis, the vertical profiles of active and break events are not simulated so well, the break phase especially exhibiting anomalous ascending vertical motions over a belt that is too

470 meridionally confined. We found that the observed near-quadrature phase relationship between

471 SST and precipitation is not represented properly over the equatorial Indian Ocean in GloSea5.

472 By using a latent heat flux decomposition method and slab ocean approach we highlighted the 473 role of low wind variance and heat flux perturbations in reducing the model's SST variability in

474 the equatorial Indian Ocean. Weaker subseasonal variance over the equatorial Indian Ocean in 
475 GloSea5 is clearly visible even in 10m zonal wind stress when compared to both QuikSCAT and 476 ERA-Interim (Fig. 13); the low wind variance in the EEIO region may itself relate to the high

477 mean winds. Simulated air-sea interactions in the equatorial central Indian Ocean are therefore 478 not supportive of initiation and northward propagation of MISO in that region, likely a result of 479 the low surface wind variance there.

\subsection{Discussion}

481 Current work diagnosing the biases in simulating MISO together with this study may motivate 482 further work on linkages between couple model mean climate and simulation of MISO, and thereby ways to improve it. Even though intraseasonal variability during the monsoon period is 484 simulated satisfactory (Fig. 4), both eastward- and northward-propagating characteristics over the tropical belt in this model framework are not satisfactory (Fig. 5). Goswami (2011) discussed the role of cyclonic vorticity and the importance of boundary layer moisture convergence ahead of maximum convection enabling the northward propagation of MISO-associated convection.

488 To elucidate it further here, regression analysis of potential vorticity anomaly (PV) in the lower 489 atmosphere and convection for Glosea5 is depicted in Fig. 14 along with observations, here PV reflects both vorticity and thermodynamic properties of the atmosphere. The lead-lag relationship

491 between convection and PV anomalies over the central equatorial Indian Ocean is also not 492 maintained properly in GloSea5 from lower levels to the middle atmosphere. Instead of a coherent phase relationship, regressed phases are stationary at the equator and $20^{\circ} \mathrm{N}$ in GloSea5.

494

495 496

497 498 499 500

501 502
According to Ajayamohan et al. (2009), disorganized northward propagation is found in situations with positive IOD-like SSTs, by modulating the propagation characteristics of convection through changes in the mean moisture convergence and meridional specific humidity. Since GloSea5 SST has a mean cold bias in the eastern equatorial Indian Ocean (Johnson et al. 2016), the aforementioned hypothesis may also be a factor for the incoherent nature of MISO propagation. On other hand, the mean EEIO cold bias could be caused largely by the lack of strong enough boreal-summer MJO activity over the equatorial Indian Ocean. With weaker westerly winds in GloSea5 here, the cross-equatorial monsoonal flow west of the Sumatra will induce strong upwelling cold water, which will be advected westward along the equatorial Indian 
Ocean. This may suppress the convective initiation associated with MISO and in turn affect the northward propagation through air-sea interaction.

Our diagnostics have pointed out the limitations of the GloSea5 seasonal forecasting model in representing the local monsoon Hadley circulation (Fig. 7d) and low-level wind variance in the equatorial Indian Ocean (Fig. 13). Joseph and Sijikumar (2004) showed that during break phases of the monsoon, the low-level winds of the Somali jet curve clockwise over the Arabian Sea under conservation of potential vorticity (Rodwell and Hoskins 1995). This shifting of the jet axis towards the equatorial region during break phases is an important feature lacking in the model (figure not shown). A budget analysis of potential vorticity including contributions from advection, momentum and diabatic heating terms from convection (radiation, cumulus physics) covering active-break events may reveal more details of the large-scale monsoon flow dynamics and their relation to the convective parameterization of the model. This analysis will be performed in a future study.

Annamalai and Sperber (2005) demonstrated that the three main heating centers during the monsoon period are located over the equatorial central-eastern Indian Ocean, the Bay of Bengal, and the tropical west Pacific; emanation of Rossby waves associated with this heating is important to the life cycle and northward propagation of MISO in addition to its modulation by air-sea interaction processes. Since our study has shown the limitation of GloSea5 in maintaining a correctly phased SST-precipitation relationship in the equatorial Indian Ocean region (Fig. $7 \mathrm{~g}$ ) and atmospheric convection is also connected to the thermodynamics of the upper ocean via low-level wind variability, we will pursue further research towards the model dynamics associated with the heating centres suggested by Annamalai and Sperber (2005). Thus the current study motivates us to address the errors in active-break monsoon heating and Rossby wave responses by performing nudging experiment in the atmospheric GCM component of GloSea5, in which wind and temperature fields on all pressure levels will be pushed toward reanalysis climatology (e.g. ERA-Interim data). By doing this experiment, we hope to quantify the impact of intraseasonal oscillations on the seasonal equatorial rainfall bias suffered in the GloSea5 model configuration. 
531 The latent heat flux decomposition of GloSea5 discussed in Fig. 11g showed anomalously weak

532 variability from the SST component as compared to observations and this may also feed back on moisture transport during the monsoon period, following the mechanism discussed by Izumo et al. (2008). They suggested that the enhanced LH/SST ratio may increase the advected moisture transport in the lower troposphere towards India, which ultimately results in increased rainfall on the west coast of India that we see in this model. The GloSea5 seasonal precipitation bias on the west coast of India and the corresponding SST bias in the Arabian Sea depicted in Fig. 1 are mostly in agreement with this mechanism. The error term in the GloSea5 latent heat flux decomposition method is slightly higher than that derived from OAFlux, and may be due to the larger non-linearity present in the model ocean response, which will be considered as the limitation of this approach.

Acknowledgements This work is carried out to meet the goals of the 'NCMRWF/MoES NMM project for seamless model development for monsoon'. AGT and SJJ gratefully acknowledge the financial support given by the Earth System Science Organization, Ministry of Earth Sciences, Government of India (Grant No. MM/SERP/Univ_Reading_UK/2013/INT-13, manuscript number MM/TURNER/RP/02) to conduct this research under Monsoon Mission. ERA-Interim data used in this study have been obtained from the ECMWF data server. Thanks to IFREMER for QuikSCAT winds and the WHOI OAFlux project for flux products.

\section{References}

Abhilash S, Sahai AK, Borah N, Chattopadhyay R, Joseph S, Sharmila S, De S, Goswami BN, Arun Kumar (2014) Prediction and monitoring of monsoon intraseasonal oscillations over Indian monsoon region in an ensemble prediction system using CFSv2. Clim Dyn doi: 10.1007/s00382013-2045-9

Ajayamohan, R.S, Rao SA.,. Luo JJ, Yamagata T (2009), Influence of Indian Ocean Dipole on boreal summer intraseasonal oscillations in a coupled general circulation model, J. Geophys Res 114:D06119. doi:10.1029/2008JD011096 
559 Annamalai H, Slingo JM (2001) Active/break cycles: diagnosis of the intraseasonal variability

560 over the Asian summer monsoon. Clim Dyn 18:85-102

561 Annamalai H, Sperber KR (2005) Regional heat sources and the active and break phases of 562 boreal summer intraseasonal (30-50 day) variability. J Atmos Sci 62:2726-274

563 Best MJ, co-authors. (2011) The Joint UK Land Environment Simulator (JULES), model 564 description-Part 1: Energy and water fluxes. Geosci Model Dev 4: 677-699, doi: 10.5194/gmd565 4-677-2011.

566 Bowler N, Arribas A, Beare S, Mylne KE, Shutts G (2009) The local ETKF and SKEB:Upgrades 567 to the MORGREPS short-range ensemble prediction system. Q J R.Meteorol Soc 135:767-776.

568 de Boyer Montégu, Madec CG, Fischer AS, Lazar A, D. Iudicone (2004) Mixed layer depth 569 over the global ocean: an examination of profile data and a profile-based climatology. J Geophys 570 Res 109:C12003

571 Duchon CE (1979) Lanczos filtering in one and two dimensions, J Appl Meteorol 18:1016-1022

572 Fu X, Wang B, Li T, McCreary JP (2003) Coupling between northward propagating, 573 intraseasonal oscillations and sea-surface temperature in the Indian Ocean. J Atmos Sci 60:1733$574 \quad 1783$

575 Goswami BN (2011) South Asian summer monsoon. In: Lau WK-M, Waliser DE (eds) 576 Intraseasonal variability of the atmosphere-Ocean climate system, 2nd edn. Springer, Berlin, pp $577 \quad 21-72$

578 Huffman GJ, Adler RF, Bolvin DT, Gu G, Nelkin EJ, Bowman KP, Hong Y, Stocker EF., Wolff 579 D.B. (2007) The TRMM Multi-satellite Precipitation Analysis: Quasi-Global, Multi-Year, 580 Combined-Sensor Precipitation Estimates at Fine Scale. J Hydrom 8:38-55

581 Hunke EC, Lipscomb WH. 2010. 'CICE: The sea icemodel documentation and software user's 582 manual, version 4.1', Technical report LA-CC-06-012. Los Alamos National Laboratory: Los 583 Alamos, NM. 
584 Izumo T, de Boyer MC, Luo JJ, Behera SK.; Sébastien M, Yamagata T (2008) The Role of the 585 Western Arabian Sea Upwelling in Indian Monsoon Rainfall Variability Journal of Climate ; 586 21(21):5603-5623. DOI: 10.1175/2008JCLI2158.1

587 Jayakumar A, Vinay Kumar, Krishnamurti TN (2013): Lead time for medium range prediction of 588 the dry spell of monsoon using multi-models. J Earth Syst Sci 122(4): 991-1004

589 Jiang X, Li T, Wang B (2004) Structures and mechanisms of the northward propagating boreal 590 summer intraseasonal oscillation. J Clim 17:1022-1039

591 Johnson S, Turner A, Woolnough S, Martin GM. MacLachlanC (2016) An assessment of Indian 592 monsoon seasonal forecasts and mechanisms underlying monsoon interannual variability in the 593 Met Office GloSea5-GC2 system. Clim Dyn doi: 10.1007/s00382-016-3151-2.

594 Joseph PV, Sabin TP (2008) An ocean-atmosphere interaction mechanism for the active break 595 cycle of the Asian summer monsoon. Clim Dyn 30:553-566

596 Joseph PV, Sijikumar S (2004) Intraseasonal variability of the lowlevel jet stream of the Asian 597 summer monsoon. J Clim 17:1449-1458

598 Kemball-Cook S, Wang B (2001) Equatorial waves and air-sea interaction in the boreal summer 599 intraseasonal oscillation. J Clim 14:2923-2942

600 Krishna Kumar K, Hoerling M, Rajagopalan B (2005) Advancing dynamical prediction of Indian 601 monsoon rainfall. Geophys Res Lett 32, L08704, doi:10.1029/2004GL021979.

602 Krishnan R, Zhang C, Sugi M (2000) Dynamics of breaks in the Indian summer monsoon. J 603 Atmos Sci 57:1354-1372.

604 Levine RC, Turner AG, Marathayil D, Martin GM (2013) The role of northern Arabian Sea 605 surface temperature biases in CMIP5 model simulations and future projections of Indian summer 606 monsoon rainfall. Clim Dyn, 41(1), 155-172.

607 MacLachlan, C, and Coauthors, 2015: Global Seasonal Forecast System version 5 (GloSea5): A 608 high resolution seasonal forecast system. Quart. J. Roy. Meteor. Soc., 141(689), 1072-1084 
609 Madec G (2008) NEMO Ocean Engine, Note du Pole de Modelisation. Institut Pierre-Simon 610 Laplace (IPSL): Paris

611 Marathayil D, Turner AG, Shaffrey LC, Levine RC (2013) Systematic winter SST biases in the 612 northern Arabian Sea in HiGEM and the CMIP3 models. Environ Res Letts 8(1), article no. 613014028.

614 Megann A, Storkey D, Aksenov Y, Alderson S, Calvert D, Graham T, Hyder P, Siddorn J, Sinha 615 B (2014) GO5.0: the joint NERC Met Office NEMO global ocean model for use in coupled and 616 forced applications. Geosci Model Dev 7:1069-1092.

617 Rae JGL, Hewitt HT, Keen AB, Ridley JK, West AE, Harris CM, Hunke EC, Walters DN (2015) 618 Development of the Global Sea Ice 6.0 CICE configuration for the Met Office global coupled 619 model. Geosci Model Dev 8:2221-2230.

620 Rajeevan M, Gadgil S, Bhate J (2010) Active and break spells of the Indian summer monsoon. 621 JEarth Sys Sci 119, 229-248.

622 Rahman, SH, Sengupta D, Ravichandran M (2009)Variability of Indian summer monsoon 623 rainfall in daily data from gauge and satellite. J Geophys Res -Atmospheres 114 doi: $624 \quad 10.1029 / 2008 J D 011694$

625 Rodwell MJ, Hoskins BJ (1995) A model of the Asian Summer Monsoon. Part II: Cross626 equatorial flow and PV behavior. J. Atmos. Sci., 52, 1341-1356.

627 Roxy M, Tanimoto Y (2007) Role of SST over the Indian Ocean in influencing the intraseasonal 628 variability of the Indian summer monsoon. J. Met. Soc. Japan, 85(3), 349-358

629 Sengupta D, Goswami BN, Senan R (2001) Coherent intraseasonal oscillations of ocean and 630 atmosphere during the Asian summer monsoon. Geophys Res Lett 28:4127-4130, 631 doi:10.1029/2001GL013587

632 Sikka DR, Gadgil S (1980) On the maximum cloud zone and the ITCZ over Indian longitudes 633 during the southwest monsoon. Mon Weather Rev 108:179-195 
634 Sperber KR, Annamalai H (2008) Coupled model simulations of boreal summer intraseasonal 635 (30-50 day) variability, Part 1: Systematic errors and caution on use of metrics Clim Dyn. 636 31:345-372 DOI 10.1007/s00382-008-0367-9

637 Sperber, KR, Annamalai H, Kang IS, Kitoh A, Moise A, Turner A, Wang B Zhou T (2013) The 638 Asian Summer Monsoon: An Intercomparison of CMIP5 vs. CMIP3 Simulations of the Late 639 20th Century. Clim Dyn 41: 2711-2744.

640 Srinivasan J, Gadgil S, Webster PJ (1993) Meridional propagation of large-scale monsoon 641 convective zones. Met Atmos Phys 52:15-35

642 Turner AG, Hannachi A (2010) Is there regime behaviour in Monsoon Convection in the Late 643 20th Century? Geophys. Res. Lett., 37, L16706, doi:10.1029/2010GL044159

644 Vialard J, Jayakumar A, Gnanaseelan C, Lengaigne M, SenguptaD, Goswami B (2011) 645 Processes of 30-90 days sea surface temperature variability in the northern Indian Ocean during 646 boreal summer. Clim Dyn 38(9-10):1901-1916

647 Walters DN, Williams KD, Boutle IA, Bushell AC, Edwards JM, FieldPR, Lock AP, Morcrette 648 CJ, Stratton RA, Wilkinson JM, Willett MR,Brooks ME, Copsey D, Earnshaw PD, Harris CM, 649 Manners JC, MacLachlanC, Palmer MD, Roberts MJ, Tennant WJ (2015) The Met Office 650 Unified Model Global Atmosphere 6.0/6.1 and JULES Global Land 6.0/6.1.0 congurations (in 651 preparation)

652 Wang B, Ding Q, Fu X, Kang I S, Jin K, Shukla J Doblas-Reyes F (2005) Fundamental 653 challenge in simulation and prediction of summer monsoon rainfall. Geophys Res Lett 32 654 doi:10.1029/2005GL022734.

655 Webster PJ, Magana VO, Palmer TN, Shukla J, Tomas RA, Yanai M, Yasunari T (1998) 656 Monsoons: processes, predictability, and the prospects for prediction. J Geophys Res 103:14451$657 \quad 14510$

658 Williams, KD, Coauthors, 2015: The Met Office Global Coupled model 2.0 (GC2) 659 configuration. Geosci. Model Dev. Discuss., 8:521-565, 2015 www.geosci-model-dev660 discuss.net/8/521/2015/doi:10.5194/gmdd-8-521-2015 
661 Wheeler M, Kiladis GN (1999) Convectively coupled equatorial waves: analysis of clouds and 662 temperature in the wavenumber frequency domain. J Atmos Sci 56:374-399

663 Wood NJ, Co-authors (2014) An inherently mass-conserving semi-implicit semi-Lagrangian 664 discretization of the deep-atmosphere global non-hydrostatic equations, Q J R Meteoro Soc, 665 volume 140(682):1505-1520.

666 Xavier P, Rahmat R, Cheong WK, Wallace E (2014) Influence of Madden-Julian Oscillation on 667 Southeast Asia rainfall extremes: Observations and predictability, Geophys Res Lett, 41, 4406668 4412, doi:10.1002/2014GL060241.

669 Zhang C (2005) Madden-Julian Oscillation. Rev Geophys. doi:10.1029/2004RG000158

670

671

672

673

674

675

676

677 
a) TRMM

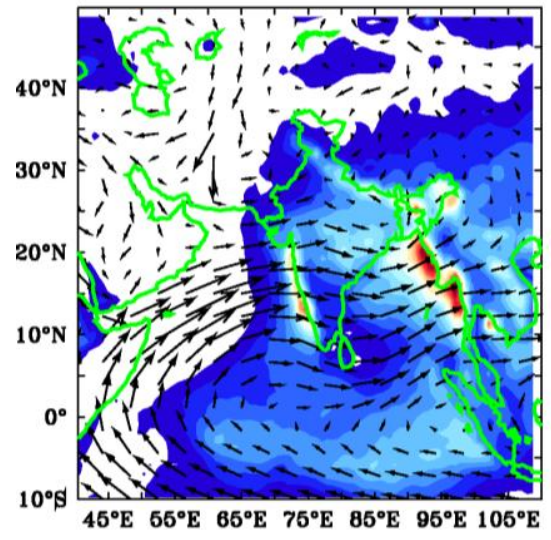

0

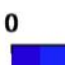

678

679

680

681

682

683

684

685

686 d) TMI

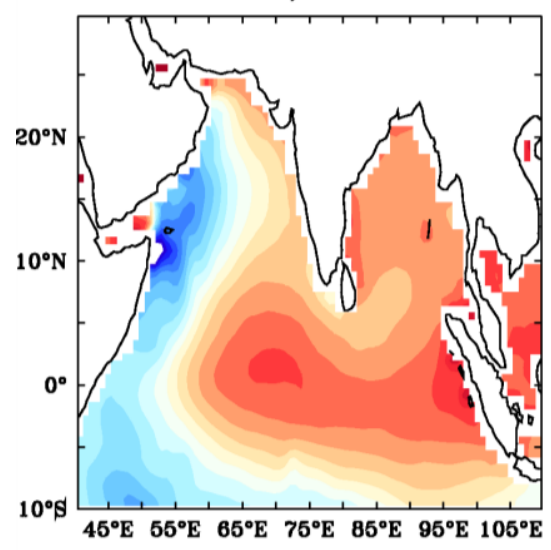

22 b) GloSea5

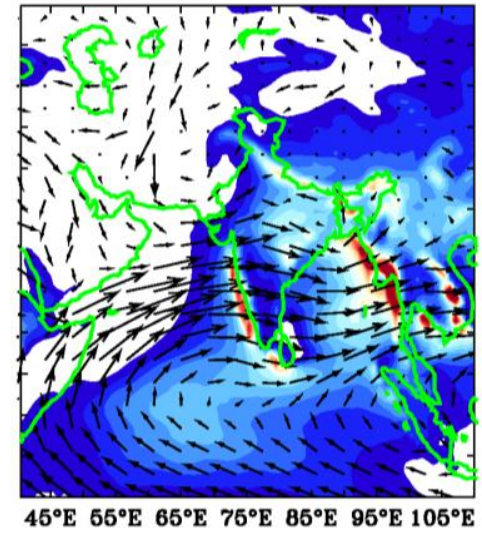
20

30

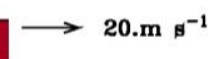

(mm)

e) GloSea5

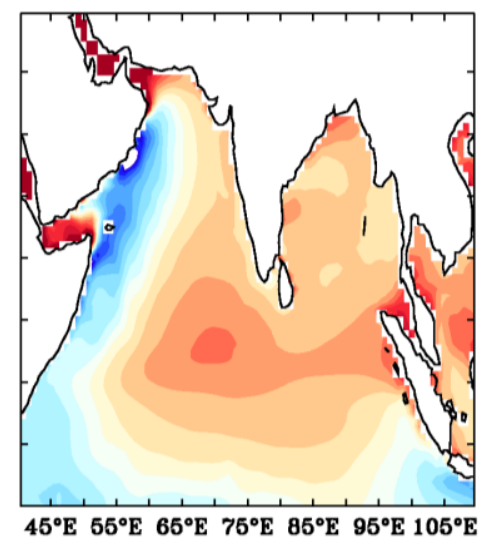

$28 \quad 30$

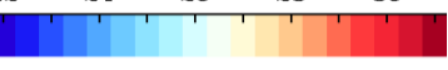

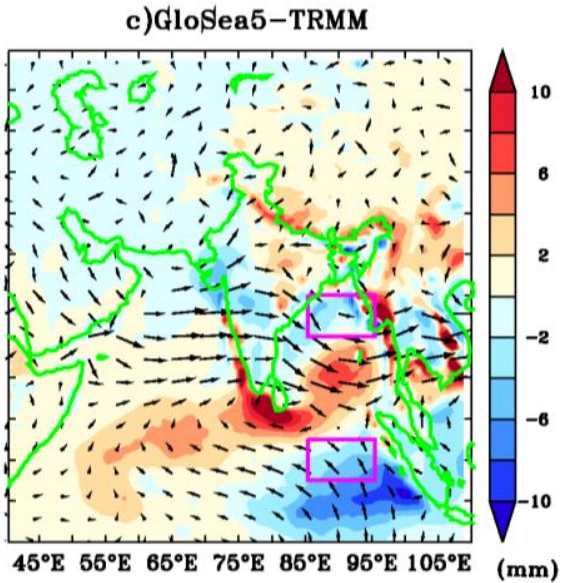

$\longrightarrow 11 . \mathrm{m} \mathrm{s}^{-1}$

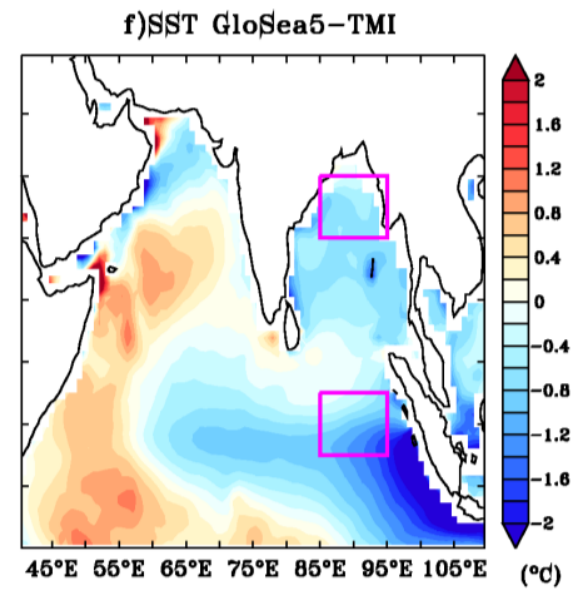

$\left({ }^{\circ} \mathrm{C}\right)$

Fig. 1 Upper panels show July/August mean precipitation (mmday ${ }^{-1}$ ) from (a) TRMM observations (1998-2013); (b) GloSea5 ensemble mean (1996-2009) and (c)their difference. Lower tropospheric $(850 \mathrm{hPa})$ wind vectors are also shown, using ERA-Interim reanalysis (19982013). Lower panels depict July/August mean SST in (d) TMI observations (1998-2013); (e) GloSea5 ensemble mean (1996-2009) and (f) their difference. The two boxes represent the Bay of Bengal $\left(\mathrm{BoB}, 85^{\circ} \mathrm{E}-95^{\circ} \mathrm{E}, 15^{\circ}-20^{\circ} \mathrm{N}\right)$ and Eastern Equatorial Indian Ocean $\left(\mathrm{EEIO}, 85^{\circ} \mathrm{E}-95^{\circ} \mathrm{E}\right.$, $\left.2.5^{\circ} \mathrm{S}-2.5^{\circ} \mathrm{N}\right)$, regions used later in this article. 
a) ERA

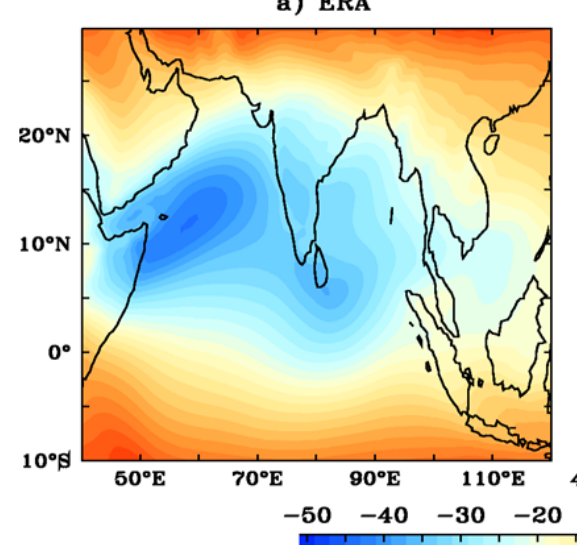

b) GloSea5
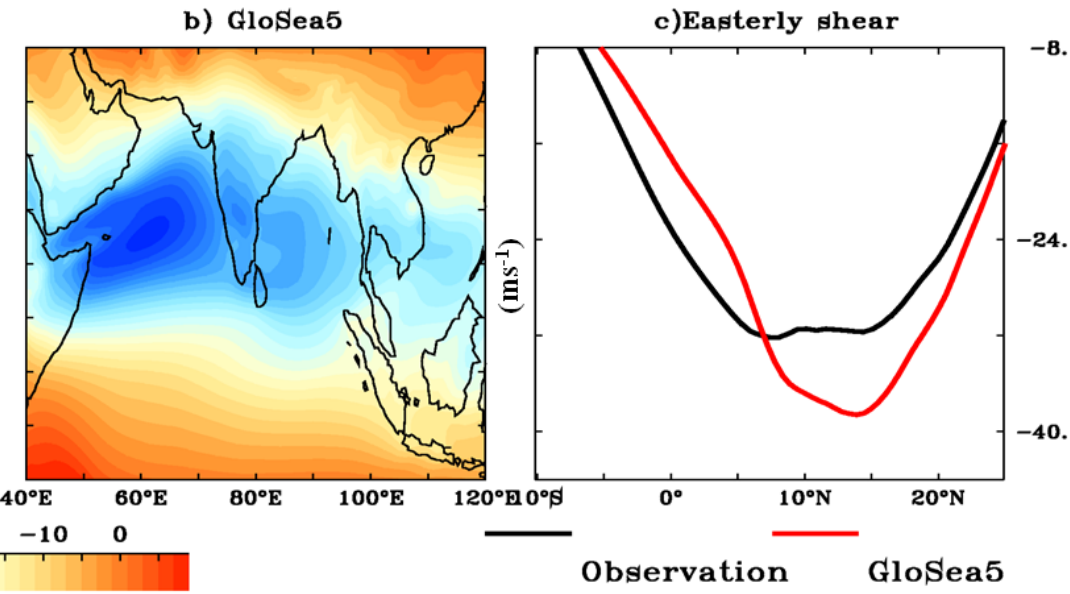

$\left(m s^{-1}\right)$

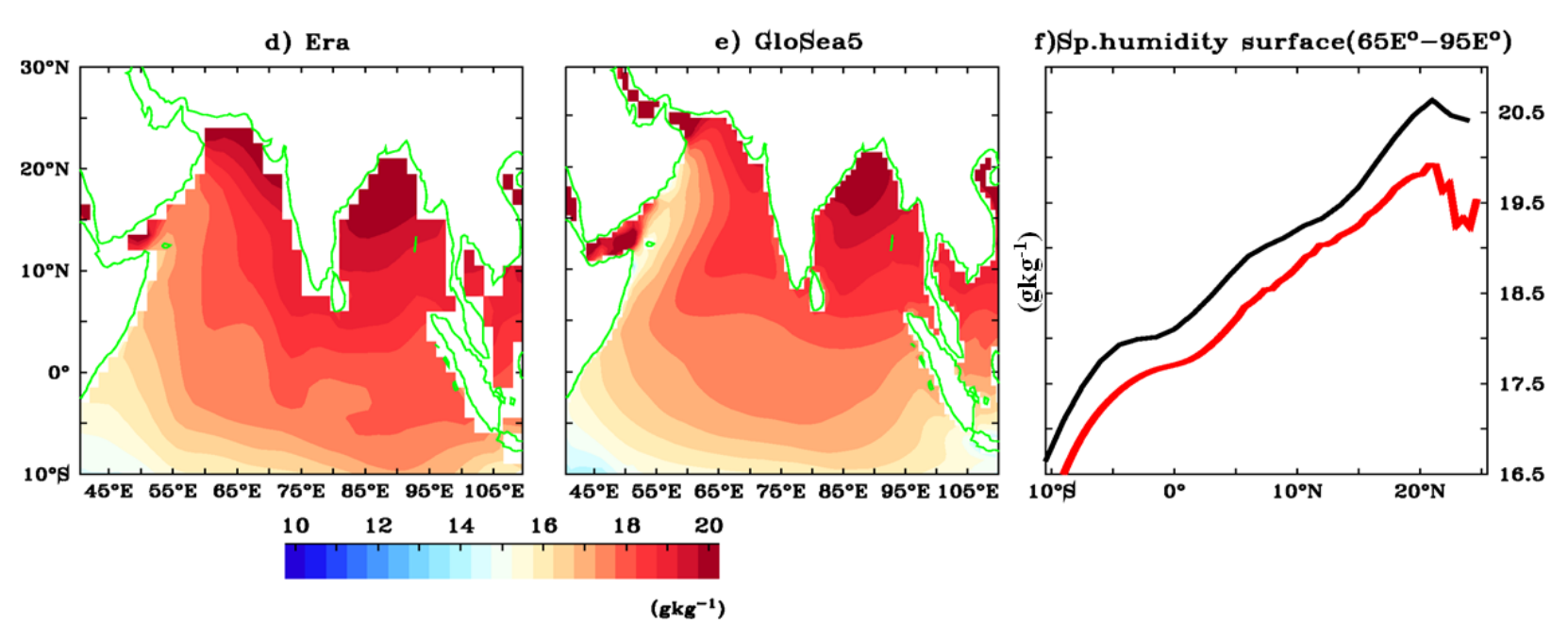

$\left(g^{k} g^{-1}\right)$

689 Fig. 2 Upper panels give July/August mean easterly wind shear (200 hPa minus $850 \mathrm{hPa})\left(\mathrm{m} \mathrm{s}^{-1}\right)$ 690 from (a) ERA-Interim reanalysis (1998-2013); (b) GloSea5 ensemble mean (1996-2009) and c) 691 zonal mean easterly wind shear over the Indian monsoon domain $\left(65^{\circ} \mathrm{E}-95^{\circ} \mathrm{E}\right)$. Lower panels

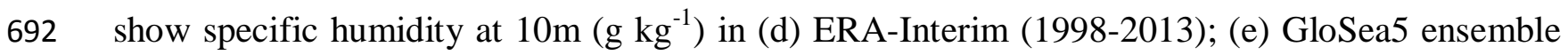
693 mean (1996-2009) and (f) their zonal mean. 
a) Mean Jul-Aug $\mathrm{MH}$

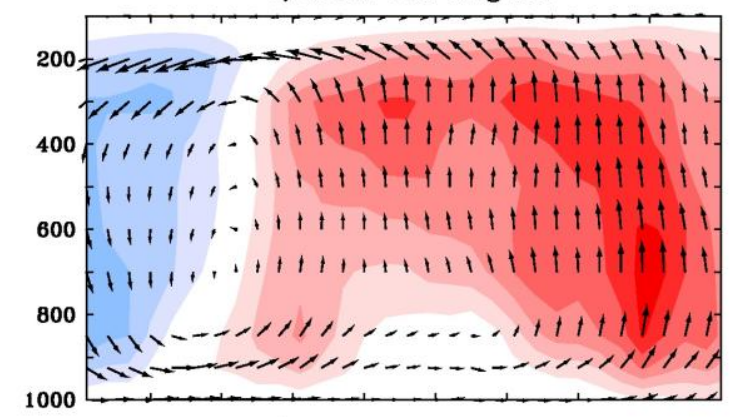

c) Mean Jul-Aug $\mathrm{MH}$

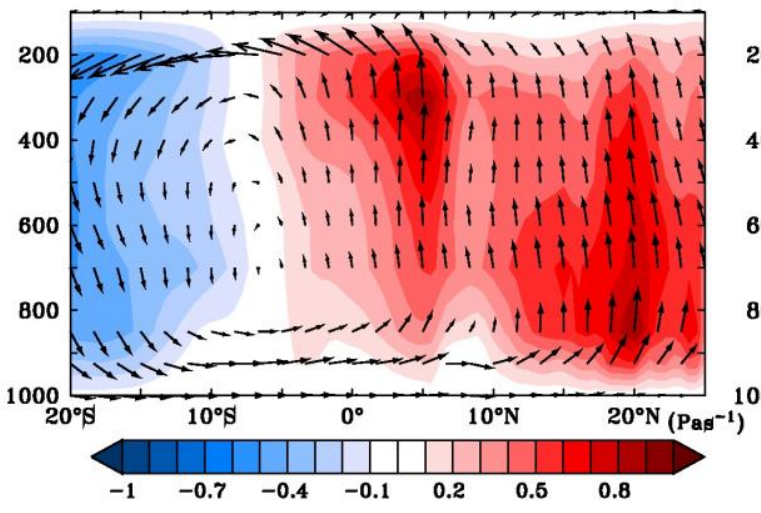

b) Mean Jul-Aug Zonal wind

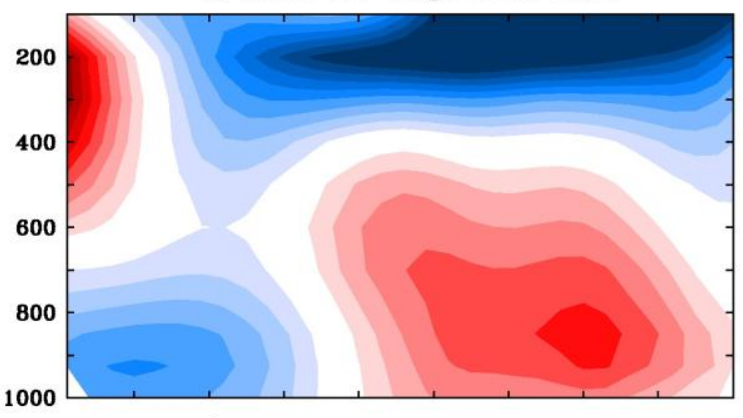

d) Mean Jul-Aug zonal wind

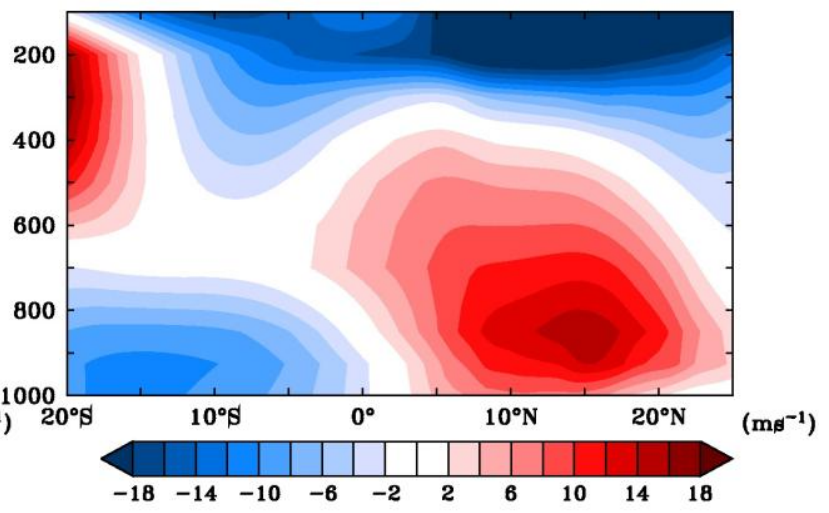

Fig. 3 Upper panels: July/August climatology of the meridional overturning circulation (known as the Monsoon Hadley circulation; MH, vectors) and vertical pressure velocity (multiplied by -

$6971, \mathrm{~Pa} \mathrm{~s}^{-1}$, shaded) zonally averaged over $65^{\circ} \mathrm{E}-95^{\circ} \mathrm{E}$ from (a) ERA-Interim (1998-2013) and (c) 698 GloSea5 ensemble mean (1996-2009). (b,d) same as (a,c) but for zonal mean zonal winds $\left(\mathrm{m} \mathrm{s}^{-1}\right)$. 

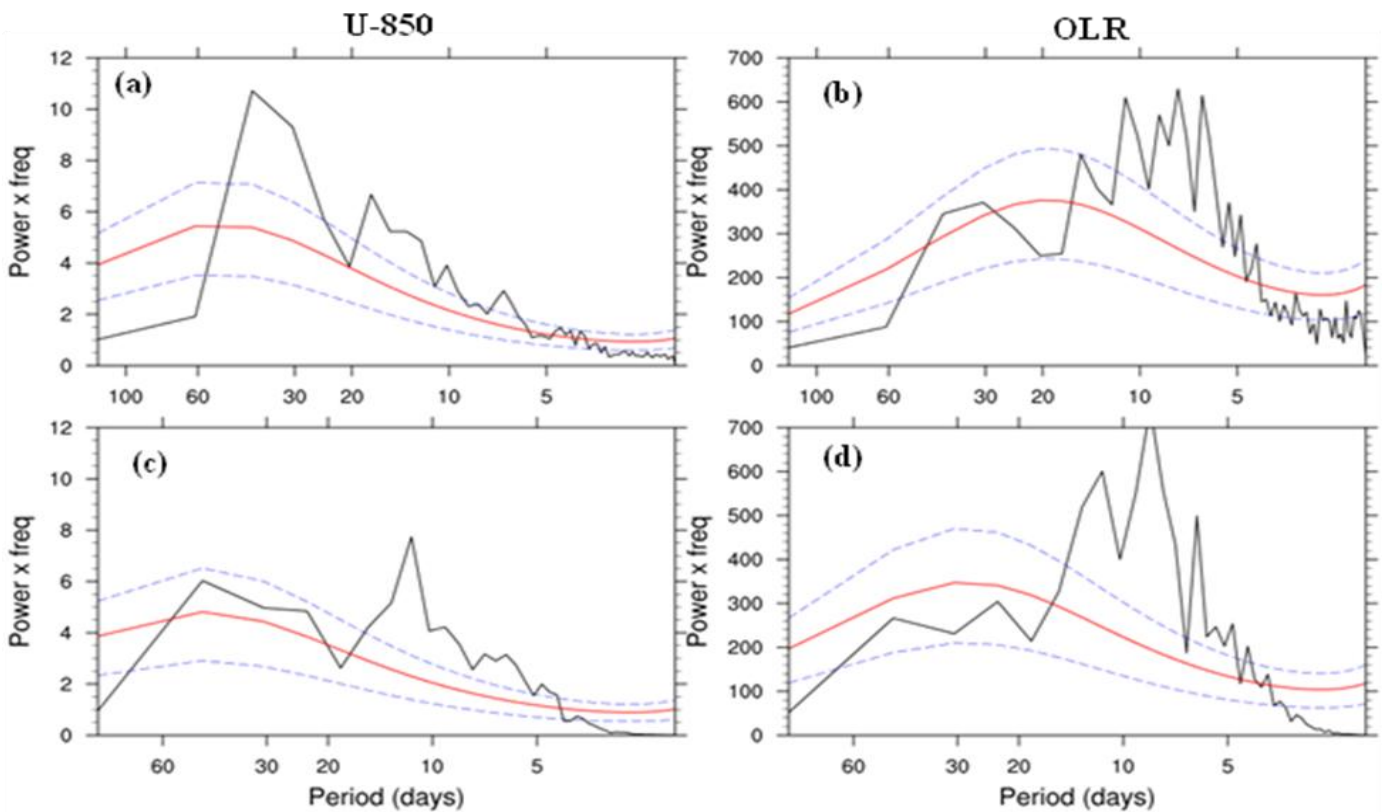

700

701

702

703

704

705

706

707

708

709

710

711

712

713

Fig. 4 Power $x$ frequency spectra from U850 wind (left) and OLR (right) from ERA-Interim reanalysis (top row: a, b) and GloSea5 (bottom row: c,d) over the Bay of Bengal (BoB). The null, 5\% and 90\% red noise significance levels are included. The period (x) axis is on a logarithmic scale. 


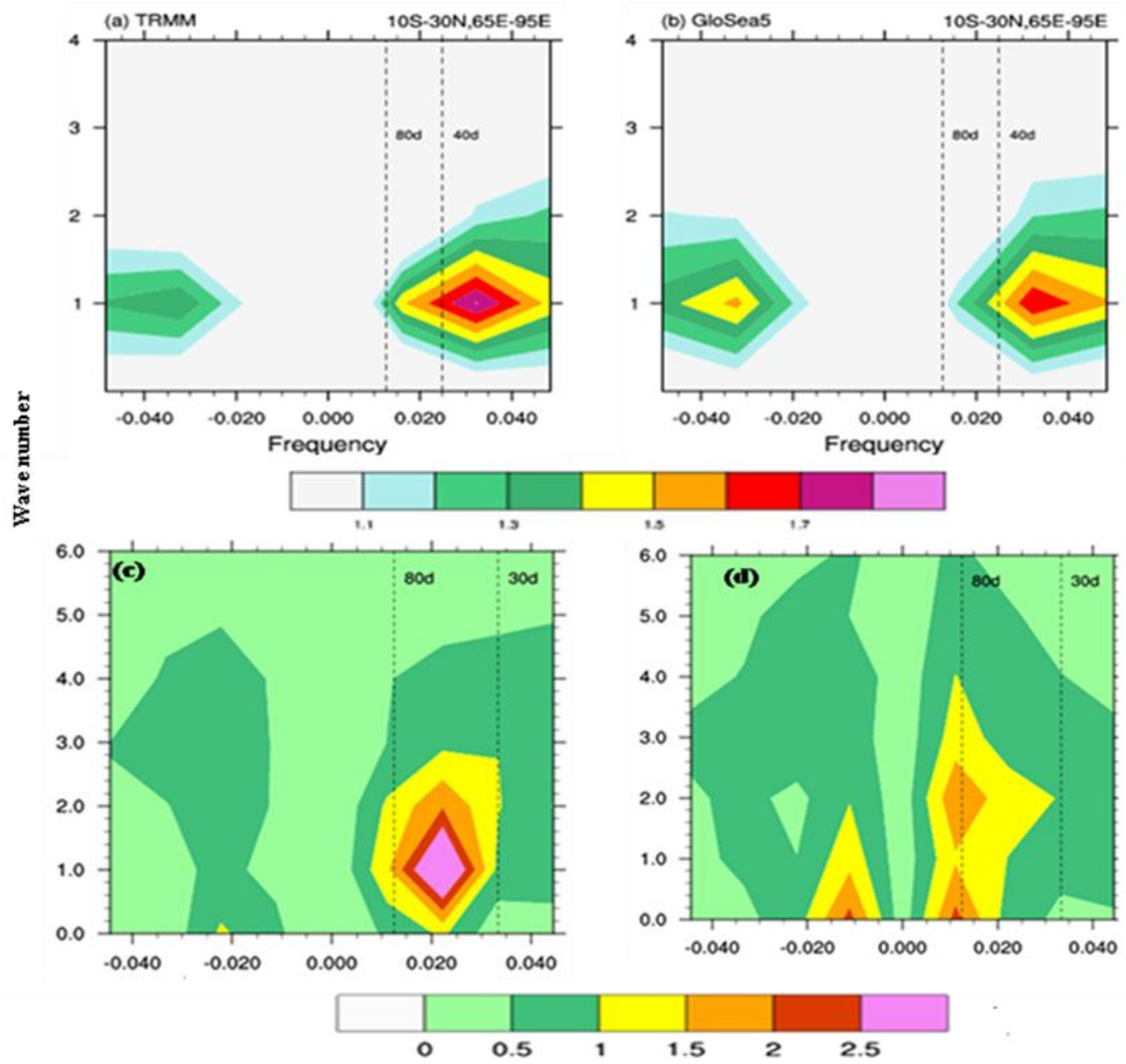

718 Fig. 5 Top panels show meridional wavenumber-frequency spectra of rainfall anomalies 719 calculated over $10^{\circ} \mathrm{S}-30^{\circ} \mathrm{N}, 60^{\circ} \mathrm{E}-95^{\circ} \mathrm{E}$ for the June-August period from (a) TRMM observations 720 and (b) GloSea5. Bottom panels show zonal wavenumber-frequency spectra of rainfall anomalies 721 calculated over the global tropics $\left(10^{\circ} \mathrm{S}-10^{\circ} \mathrm{N}\right)$ from (c) TRMM observations and (d) GloSea5 722 for the same period. 
a) lag $=-12$ days

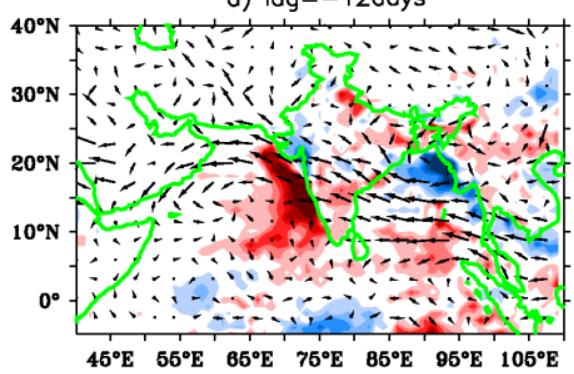

d) lag $=-3$ days

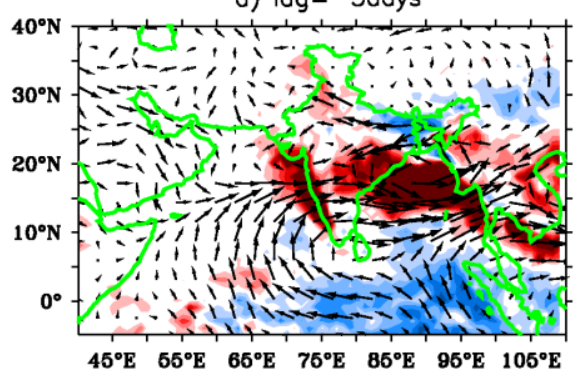

g) $\log =6$ days

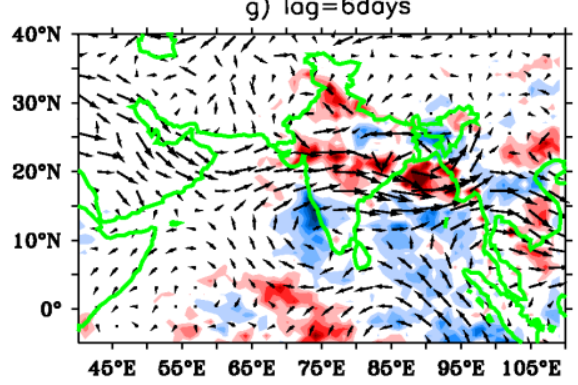

b) $\log =-9$ days

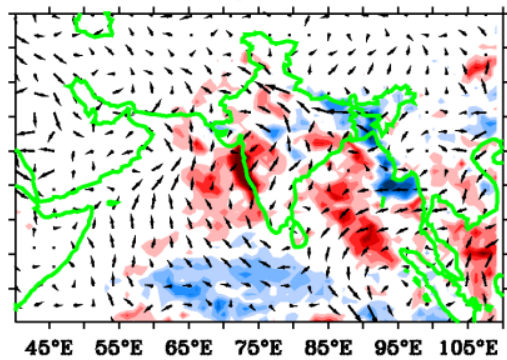

e) log=0days

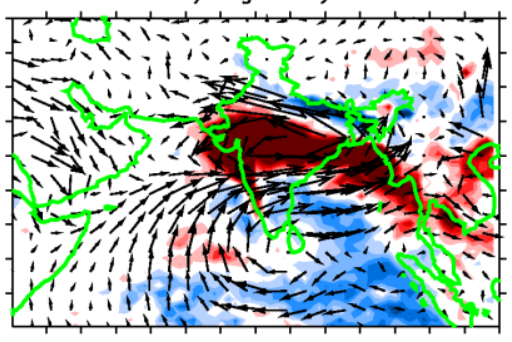

$45^{\circ} \mathrm{E} 65^{\circ} \mathrm{E} 66^{\circ} \mathrm{E} \quad 75^{\circ} \mathrm{E} \quad 85^{\circ} \mathrm{E} \quad 95^{\circ} \mathrm{E} 105^{\circ} \mathrm{E}$

h) lag=9days

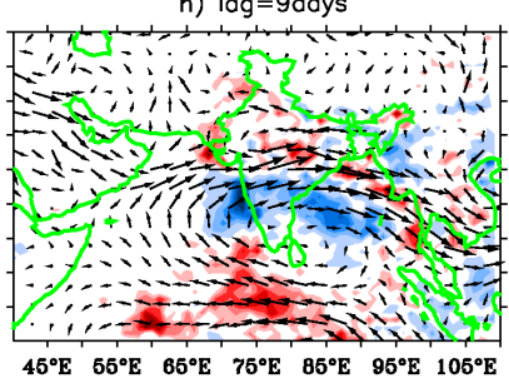

$45^{\circ} \mathrm{E} \quad 5^{\circ} \mathrm{E} \quad 65^{\circ} \mathrm{E} \quad 7^{\circ} \mathrm{E} \quad 85^{\circ} \mathrm{E} \quad 95^{\circ} \mathrm{E} \quad 105^{\circ} \mathrm{E}$ c) lag $=-6$ days

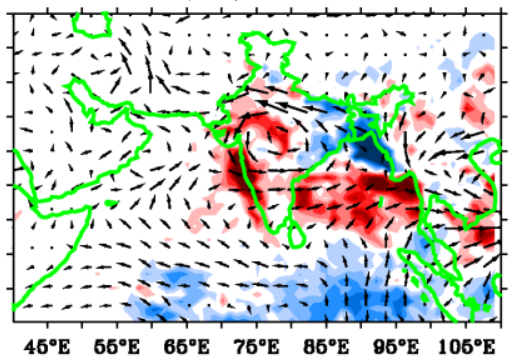

f) $\log =3$ days

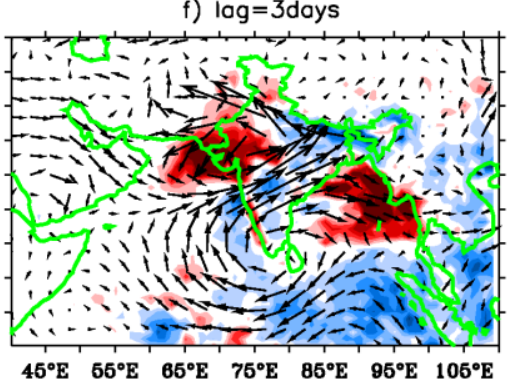

i) $\log =12$ days

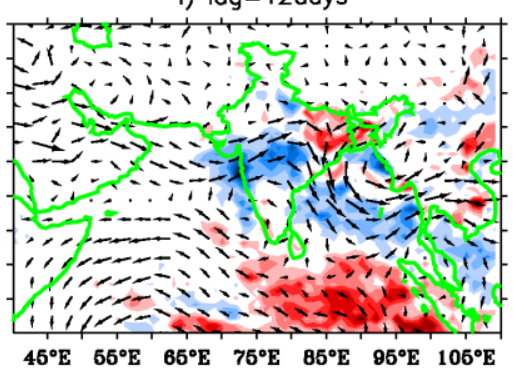

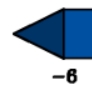

729 Fig. 6a Lagged composite diagram of TRMM precipitation anomaly (mmday ${ }^{-1}$, shaded) overlaid

730 with $850 \mathrm{hPa}$ wind anomaly from ERA-Interim reanalysis $\left(\mathrm{ms}^{-1}\right.$, vector) for 34 observed active

731 events (see text for details of compositing). 
a) lag $=-12$ days

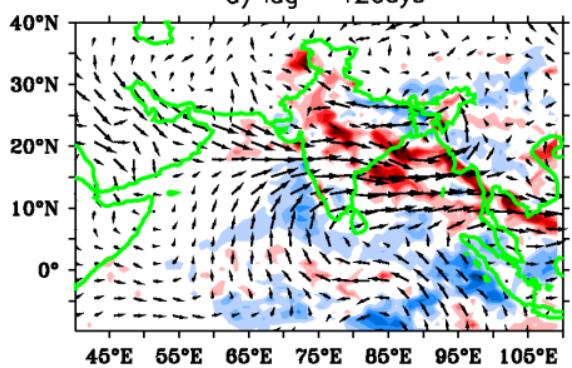

d) $\operatorname{lag}=-3$ days

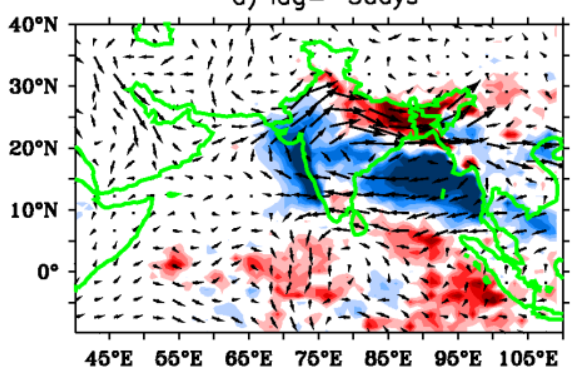

g) lag=6days

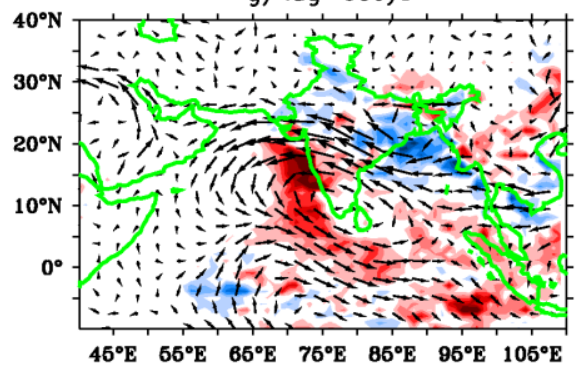

b) $\log =-9$ days

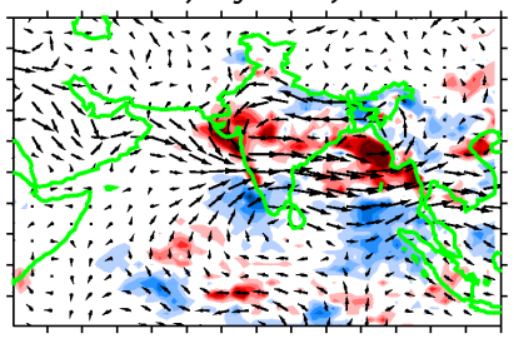

$\begin{array}{lllllll}45^{\circ} \mathrm{E} & 55^{\circ} \mathrm{E} & 65^{\circ} \mathrm{E} & 75^{\circ} \mathrm{E} & 85^{\circ} \mathrm{E} & 95^{\circ} \mathrm{E} & 105^{\circ} \mathrm{E}\end{array}$

e) lag=0days

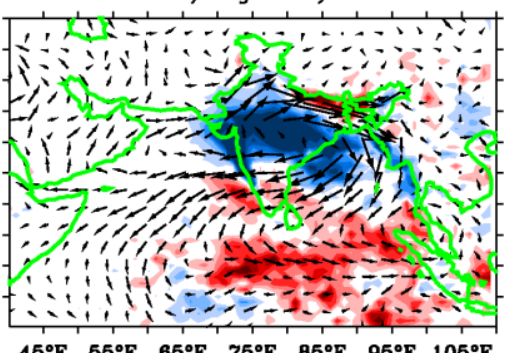

$4^{\circ} \mathrm{E} \quad 6^{\circ} \mathrm{E} \quad 66^{\circ} \mathrm{E} \quad 75^{\circ} \mathrm{E} \quad 8^{\circ} \mathrm{E} \quad 96^{\circ} \mathrm{E} 105^{\circ} \mathrm{E}$

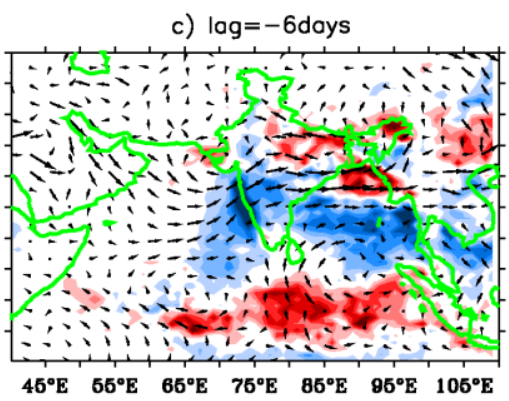

f) $\log =3$ days

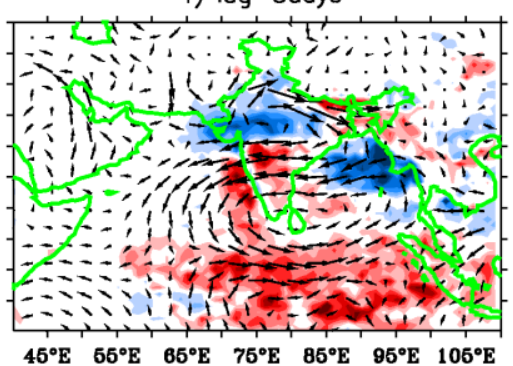

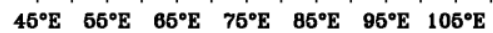

i) $\log =12$ days
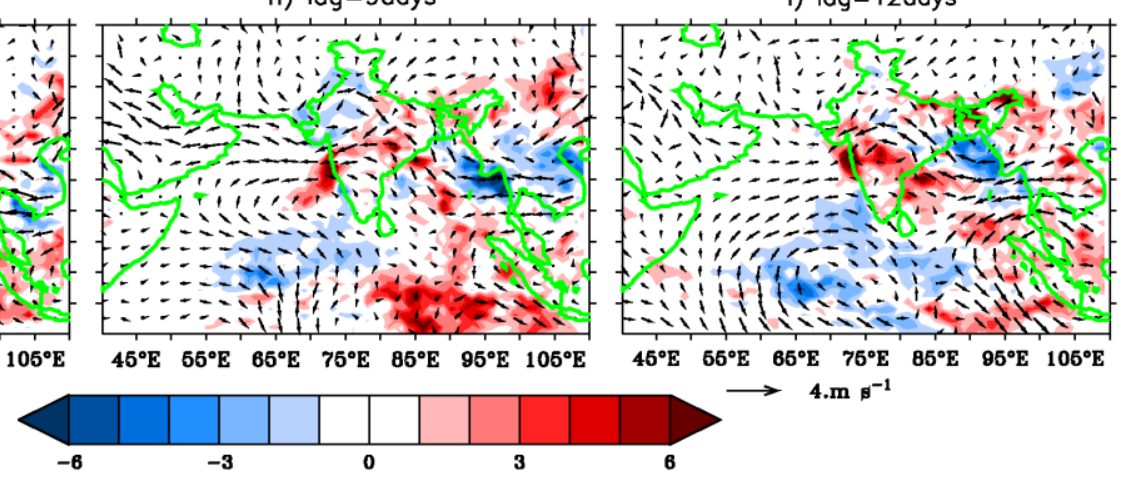

Fig. 6b same as Fig. 6a but for 35 observed break events. 
a) lag=-12days

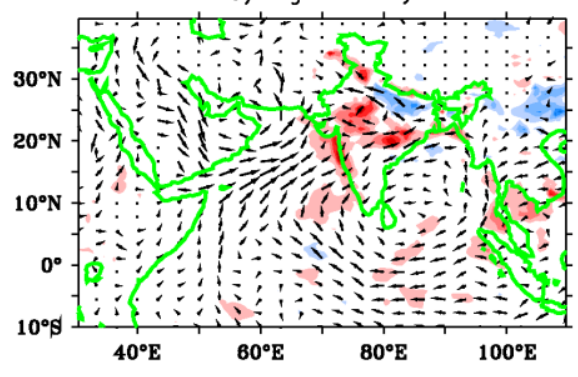

d) $\operatorname{lag}=-3$ days

g) lag=6days

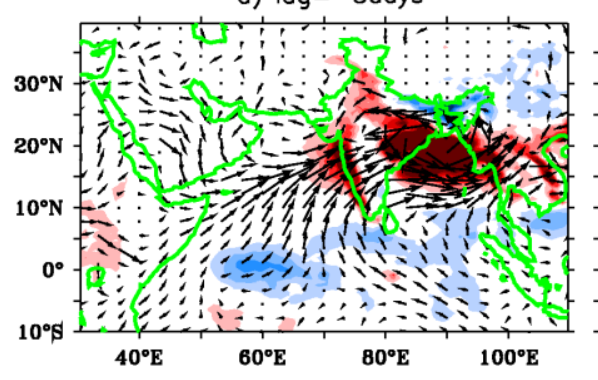

b) log= $=9$ days

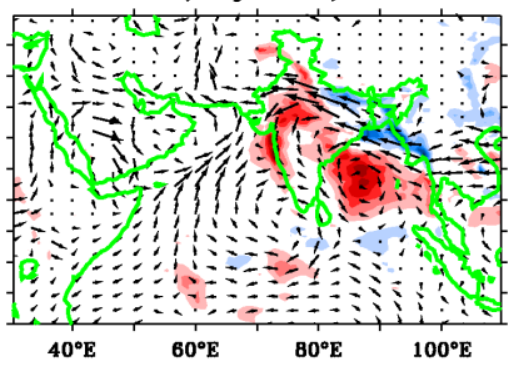

e) lag=0days

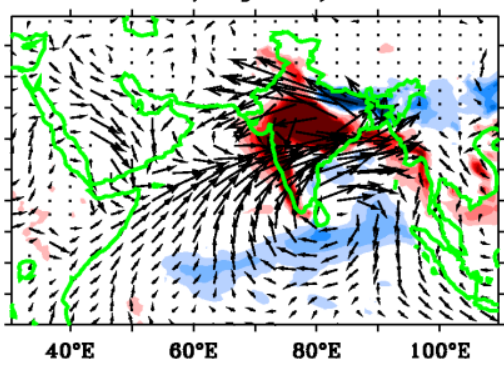

h) log=9days c) lag $=-6$ days

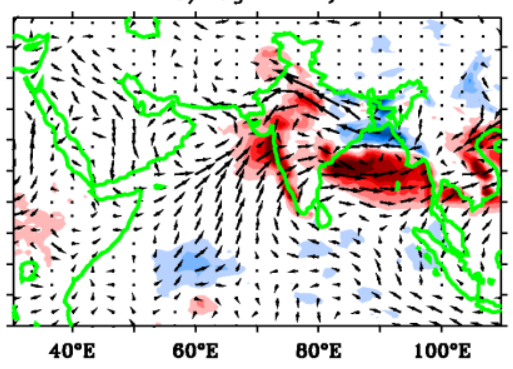

f) lag=3days

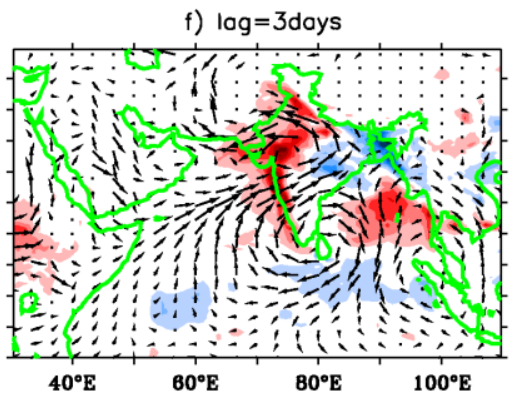

i) $\log =12$ days

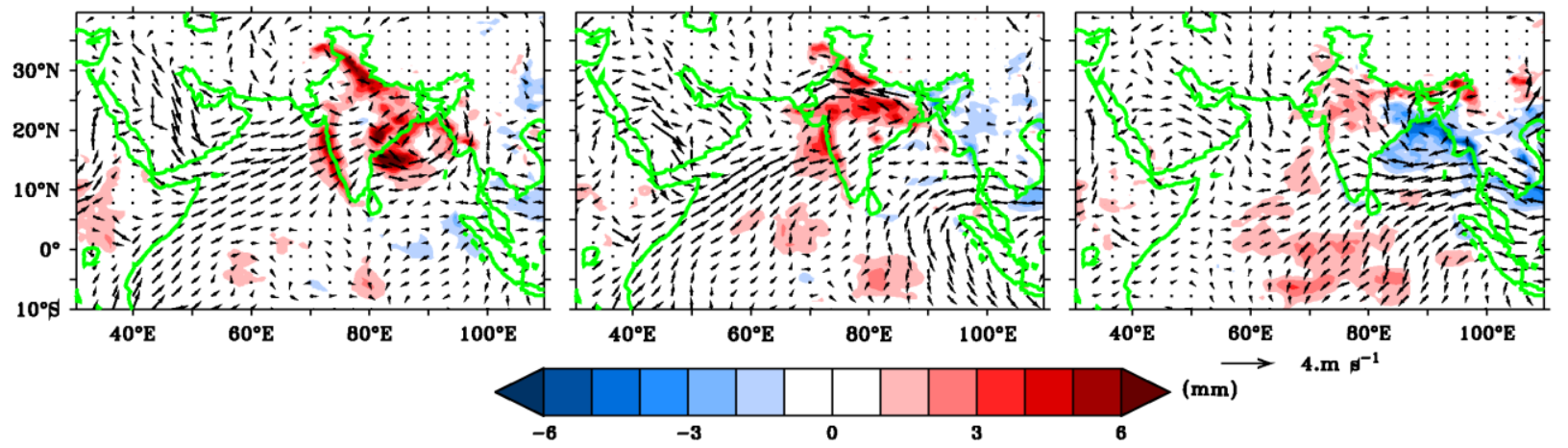

734

735

736

737

738

Fig. 6c Lagged composite diagram of GloSea5 precipitation anomalies (mmday ${ }^{-1}$, shaded) overlaid with $850 \mathrm{hPa}$ wind anomalies $\left(\mathrm{ms}^{-1}\right.$, vector) for $\sim 240$ active events identified in the GloSea5 hindcast set. 
a) lag $=-12$ days

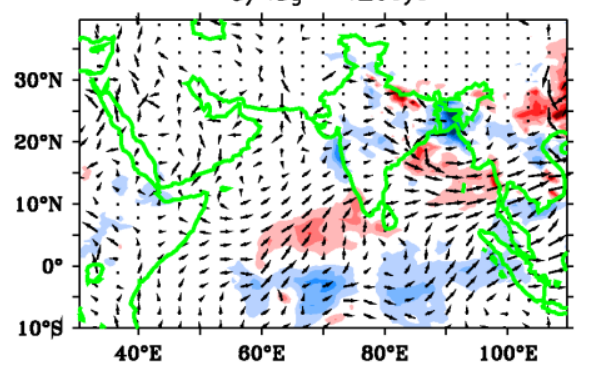

d) $\log =-3$ days

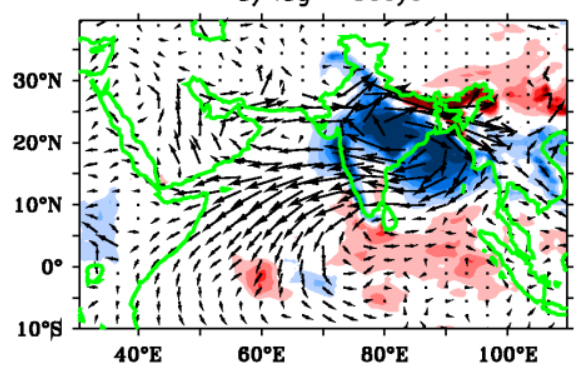

g) lag=6days

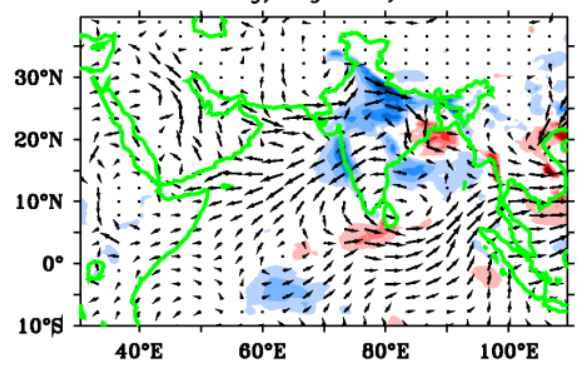

b) $\log =-9$ days

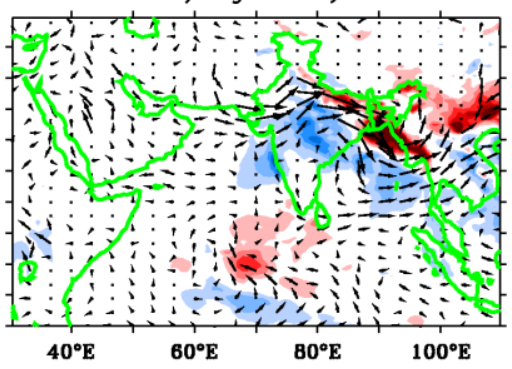

e) log=0days

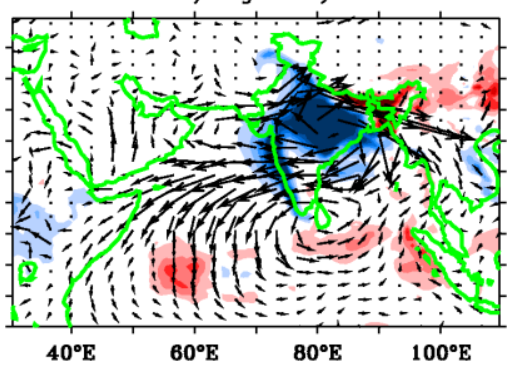

h) lag=9days

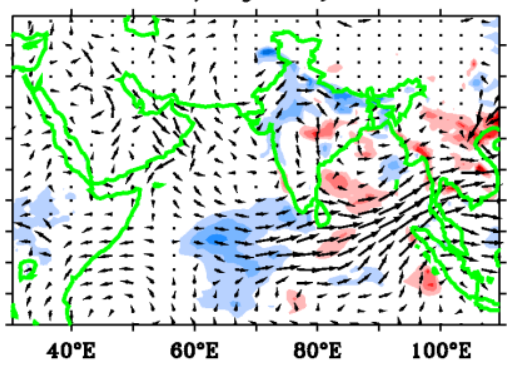

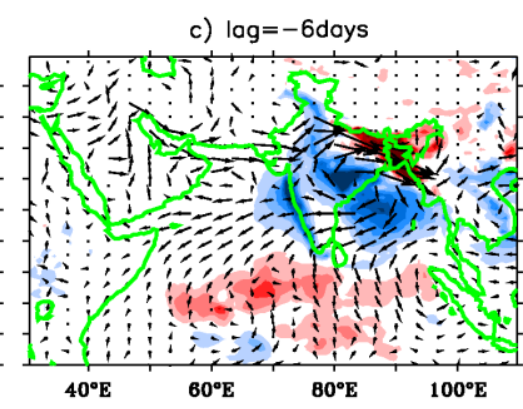

f) $\log =3$ days

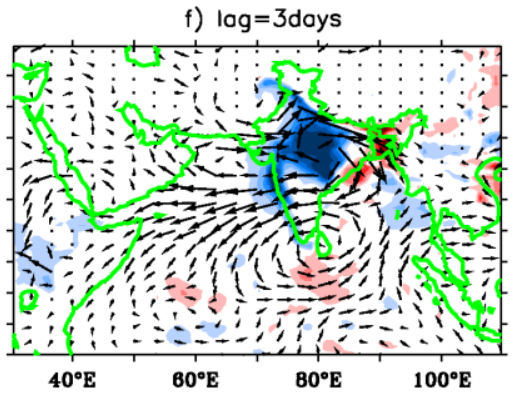

i) $\log =12$ days

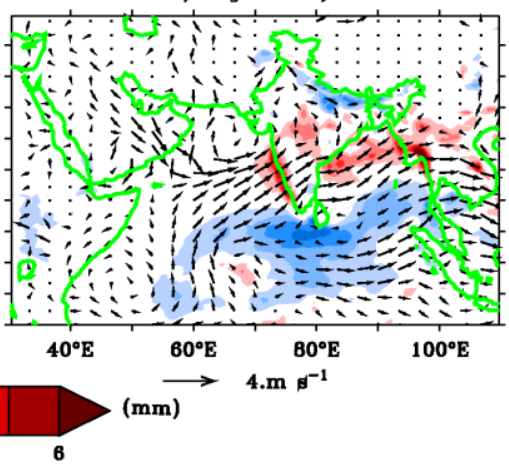

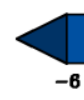

741 Fig. 6d same as Fig. 6c but for 135 GloSea5 break events. 
a) Active

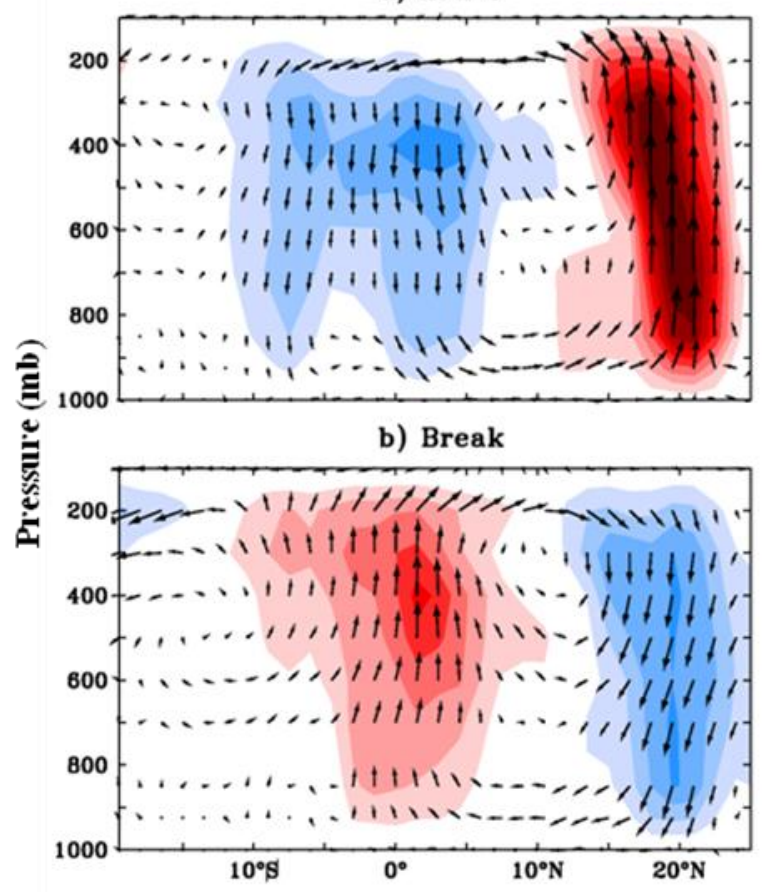

c) Active

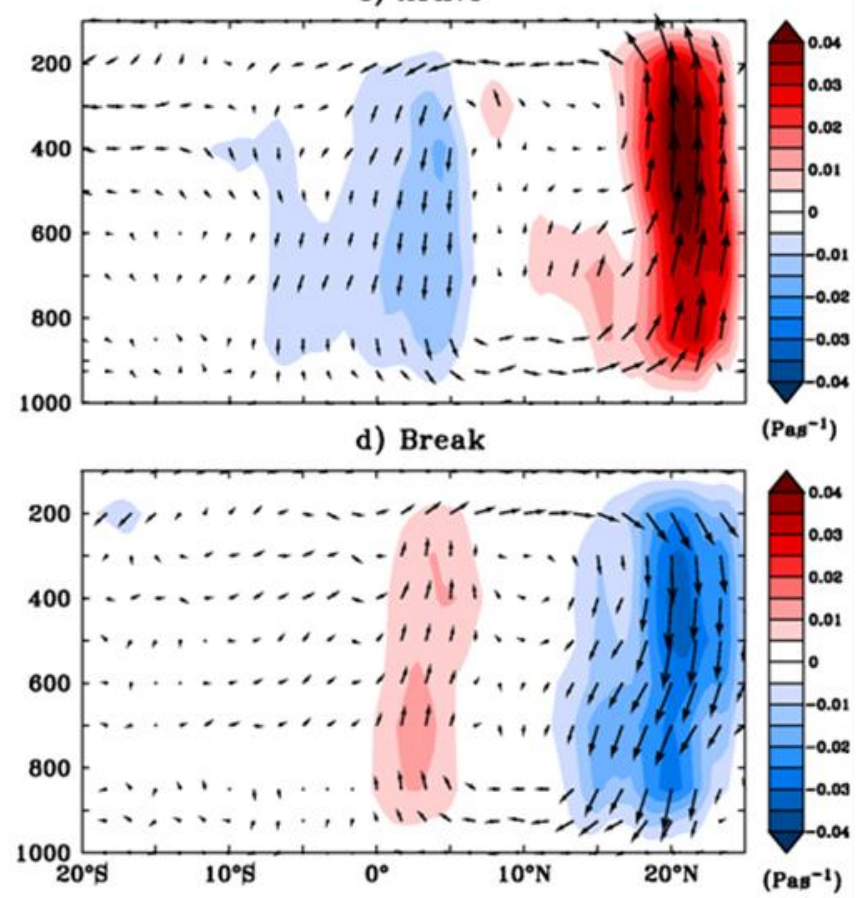

Fig. 7 Anomalous meridional overturning or local Monsoon Hadley circulation (vector) and vertical pressure velocity (multiplied by $-1, \mathrm{Pas}^{-1}$, shaded) zonally averaged over $65^{\circ} \mathrm{E}-95^{\circ} \mathrm{E}$ calculated for ERA-Interim reanalysis (a) active and (b) break events and GloSea5 model (c) active and (d) break events. 
a) Active

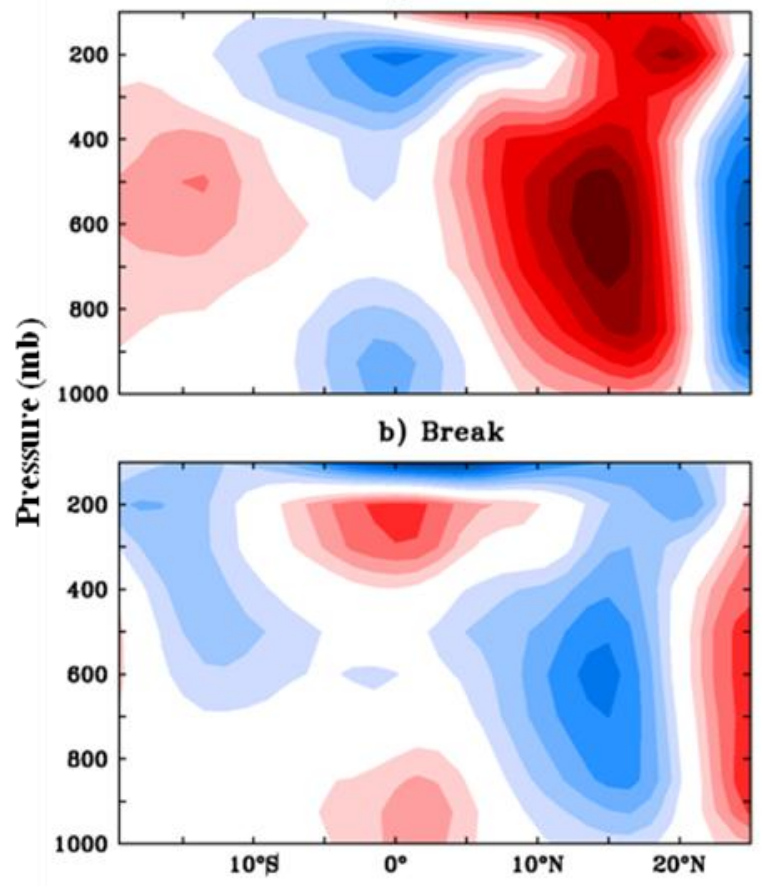

c) Active

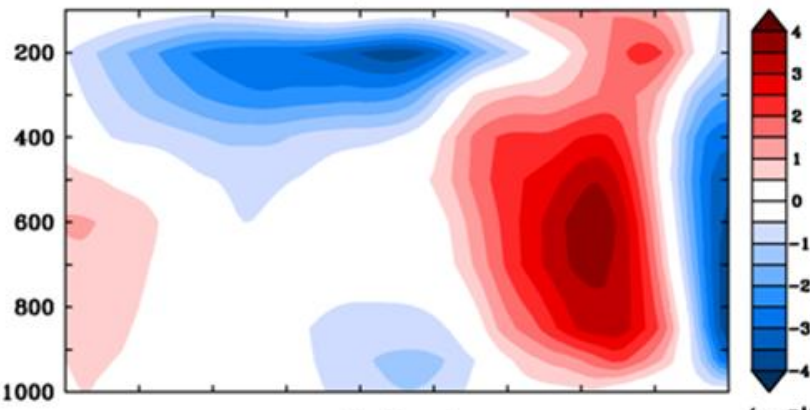

d) Break

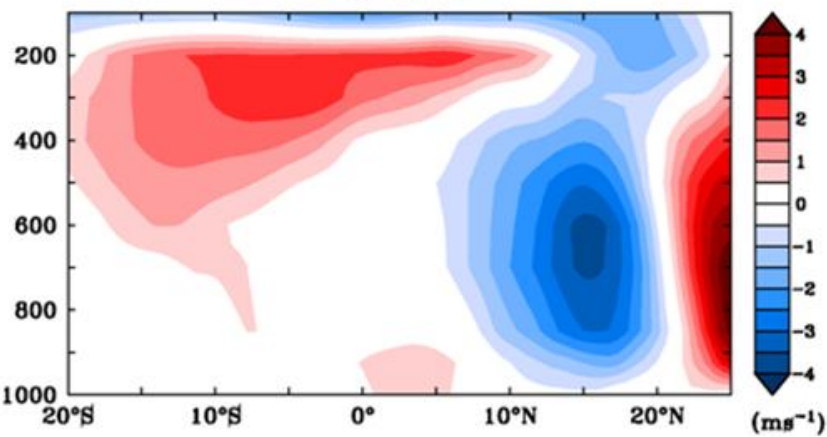

750

751

752

753

754

Fig. 8 Anomalous zonal wind $\left(\mathrm{ms}^{-1}\right)$, zonally averaged over $65^{\circ} \mathrm{E}-95^{\circ} \mathrm{E}$ calculated for ERAInterim reanalysis (a) active and (b) break events and GloSea5 model (c) active and (d) break events 

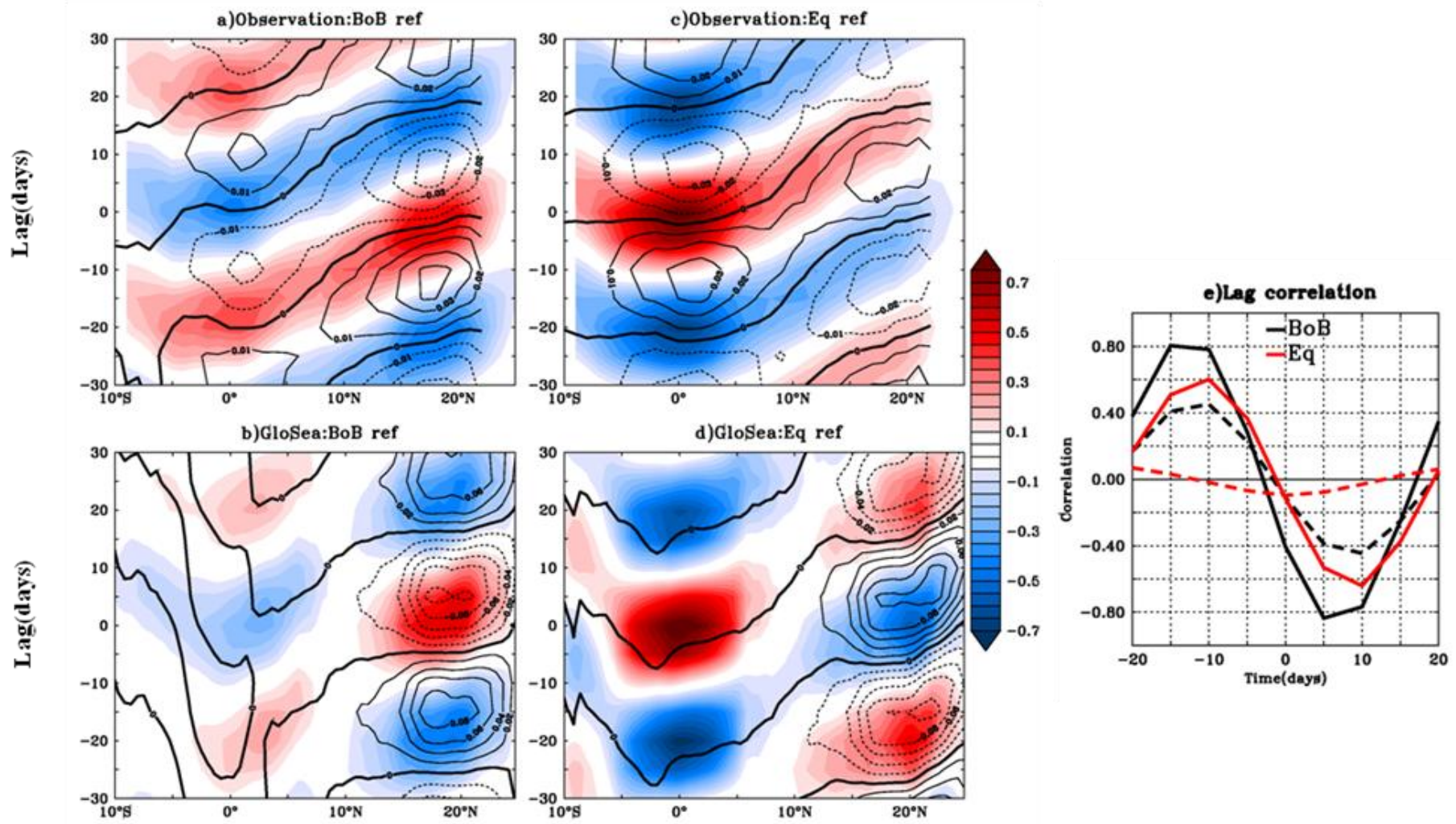

756 Fig. 9 Regressed 30-60-day bandpass-filtered anomalies of precipitation (in mm; shaded) and

757 SST (contours) zonally averaged over $70^{\circ} \mathrm{E}$ to $90^{\circ} \mathrm{E}$, with respect to a reference time series of 30 -

75860 day bandpass-filtered precipitation over BoB (left column) and Eq (right column) from

759 TRMM precipitation and TMI SST observations (a, c) and GloSea5 model precipitation and

760 SST (b, d) over the lag range of \pm 30 days. Solid (dashed) contour lines indicate positive

761 (negative) SST correlations, with thick contours showing the zero line. Panel (e) shows lead-lag

762 correlations of filtered anomalies of precipitation with SST box-averaged over the BoB (black curve) and Eq (red curve) from observations (solid) and GloSea5 (dashed). 

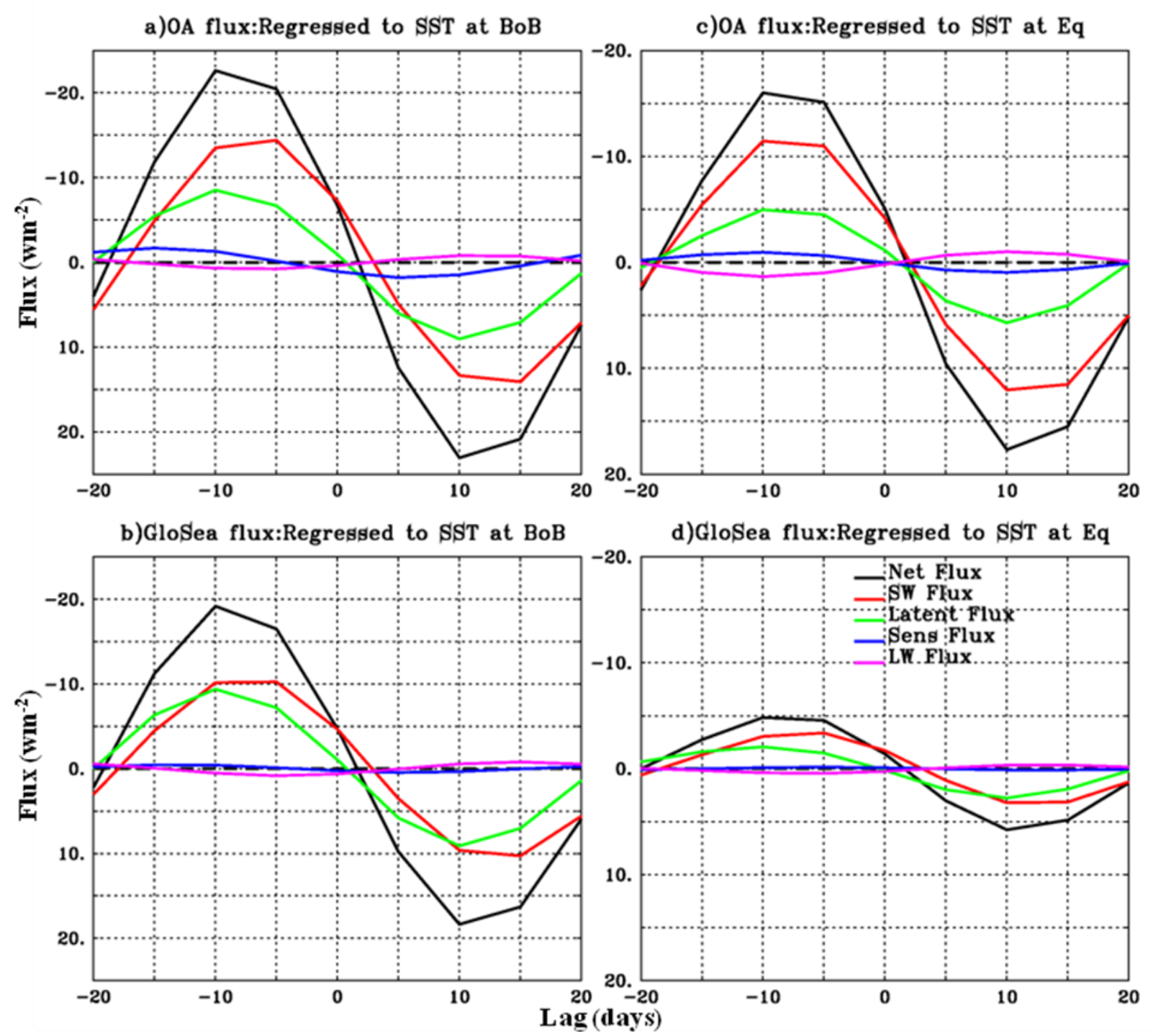

Fig. 10 June-August 30-60 day bandpass filtered net heat flux (black) and its four components (shortwave radiation in red, latent heat flux in green, sensible heat flux in blue and longwave radiation in purple) regressed onto normalized average 30-60 day bandpass-filtered SST for BoB and Eq from OA Flux (a,c) and GloSea5 (b,d). 
OA Flux
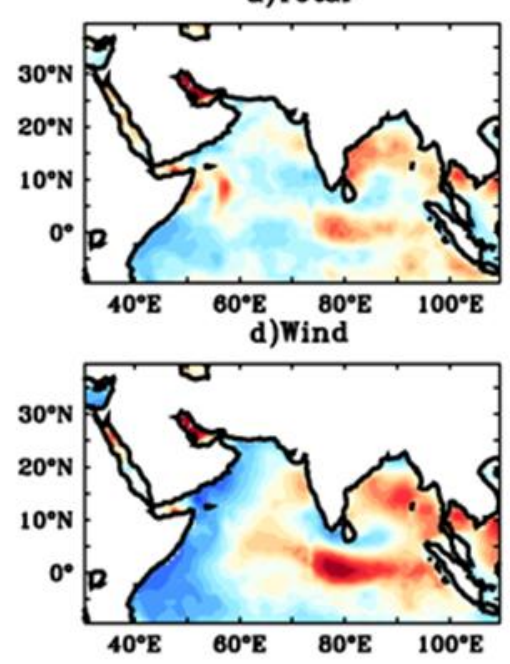

GloSea5 Flux
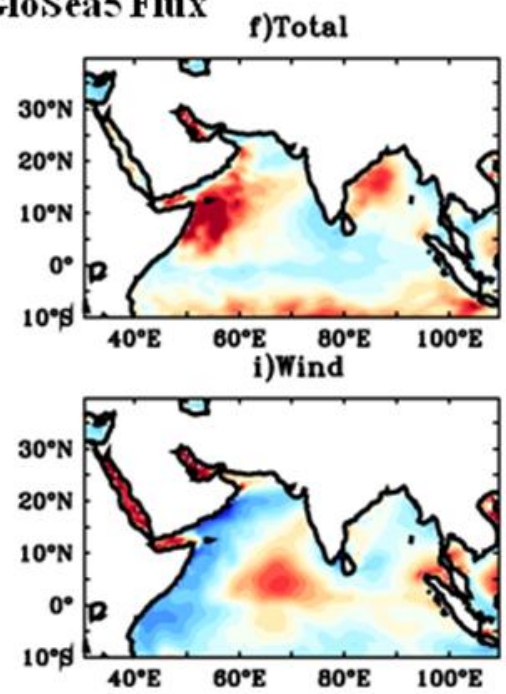

770

771 Fig. 11 Standard deviation of 30-60 day filtered latent heat flux and its decomposition terms

772 (see text for details) for OA flux observations (a-e) and GloSea5 (f-j)
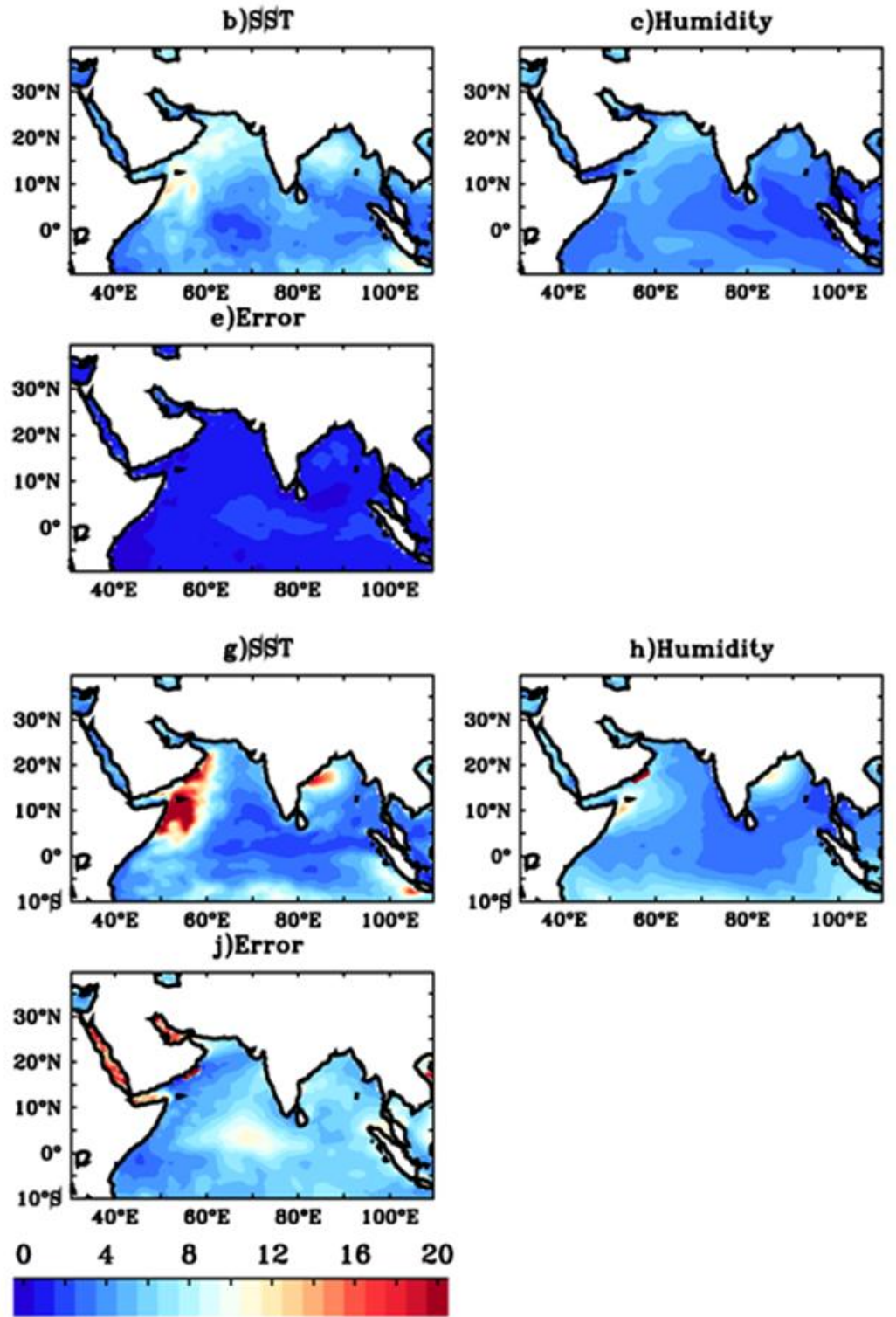

$\left(w m^{-2}\right)$

773

774

775 

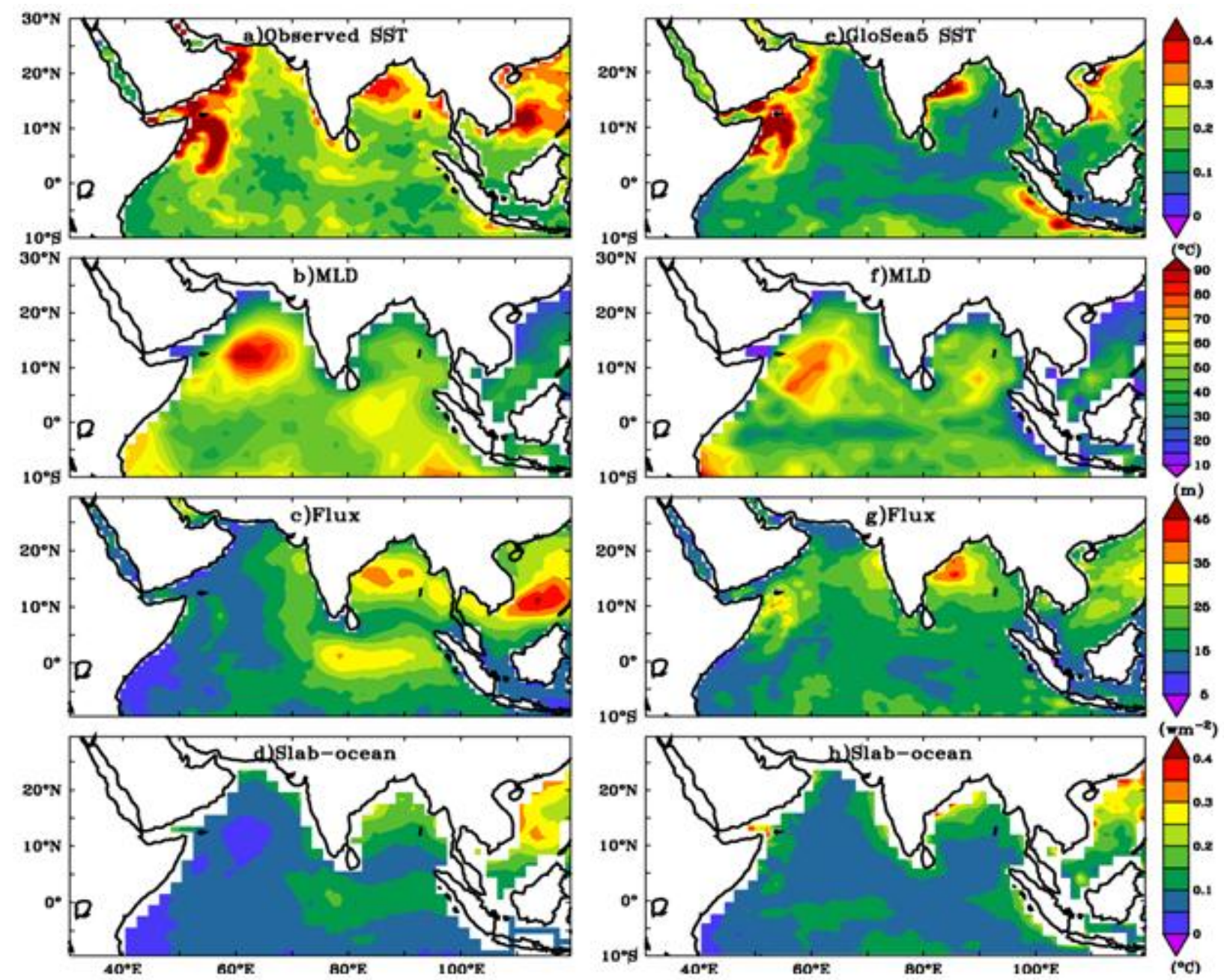

780 Fig. 12 Standard deviation of 30-60 day bandpass-filtered SST from (a) TMI observations and

(e) GloSea5, and the standard deviation of 30-60 day bandpass-filtered SST variability estimated

782 using a slab-ocean approach from (d) observations and (h) GloSea5. The mixed layer depth

783 (MLD) and net heat flux used to calculate the slab ocean variability are shown for observations 784 (b, c) and GloSea5 (f, g). 

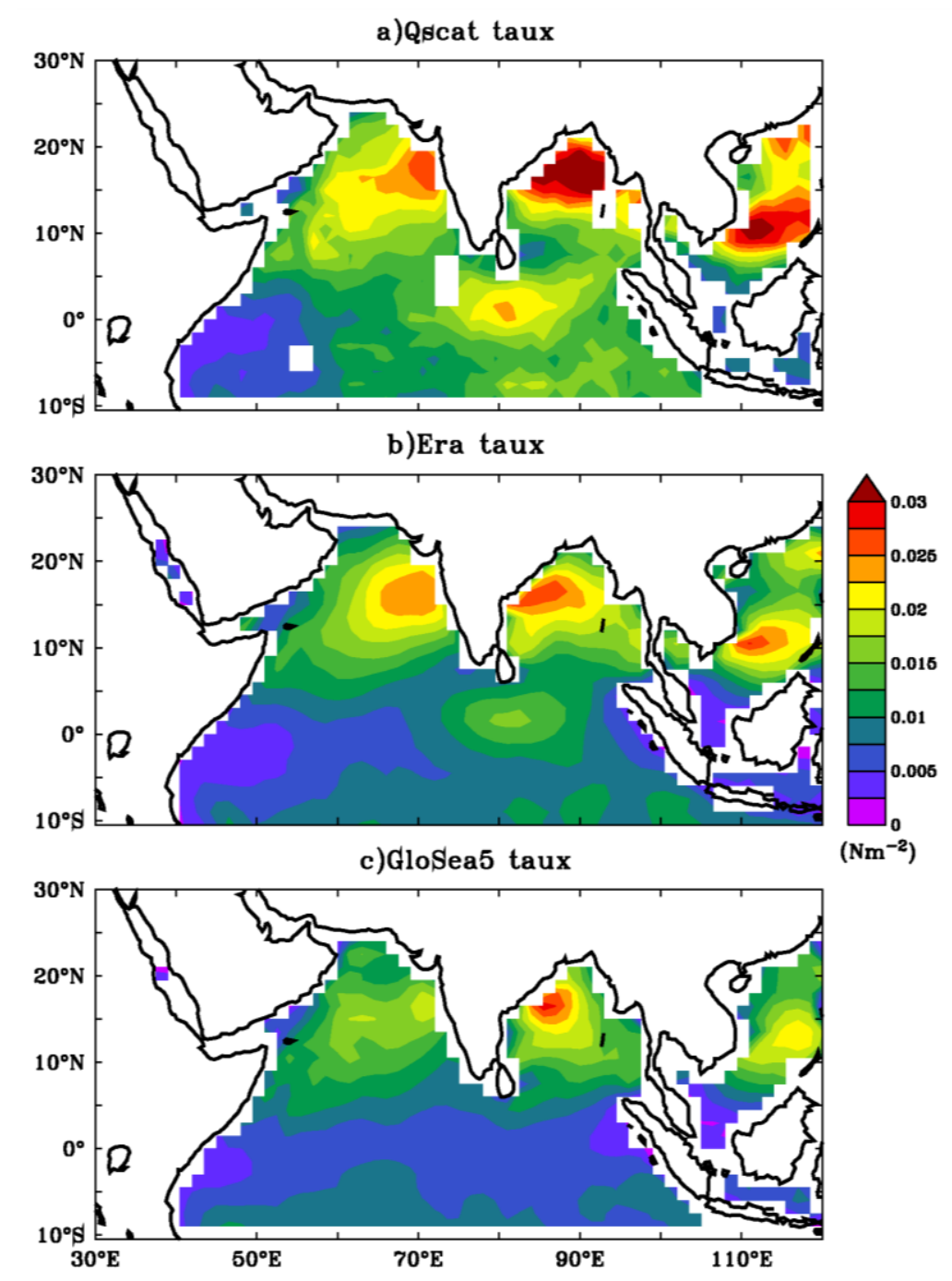

789 Fig. 13 Standard deviation of 30-60 day bandpass-filtered 10m zonal wind stress from (a) 790 QuikScat, (b) ERA-Interim Reanalysis, and (c) GloSea5. 

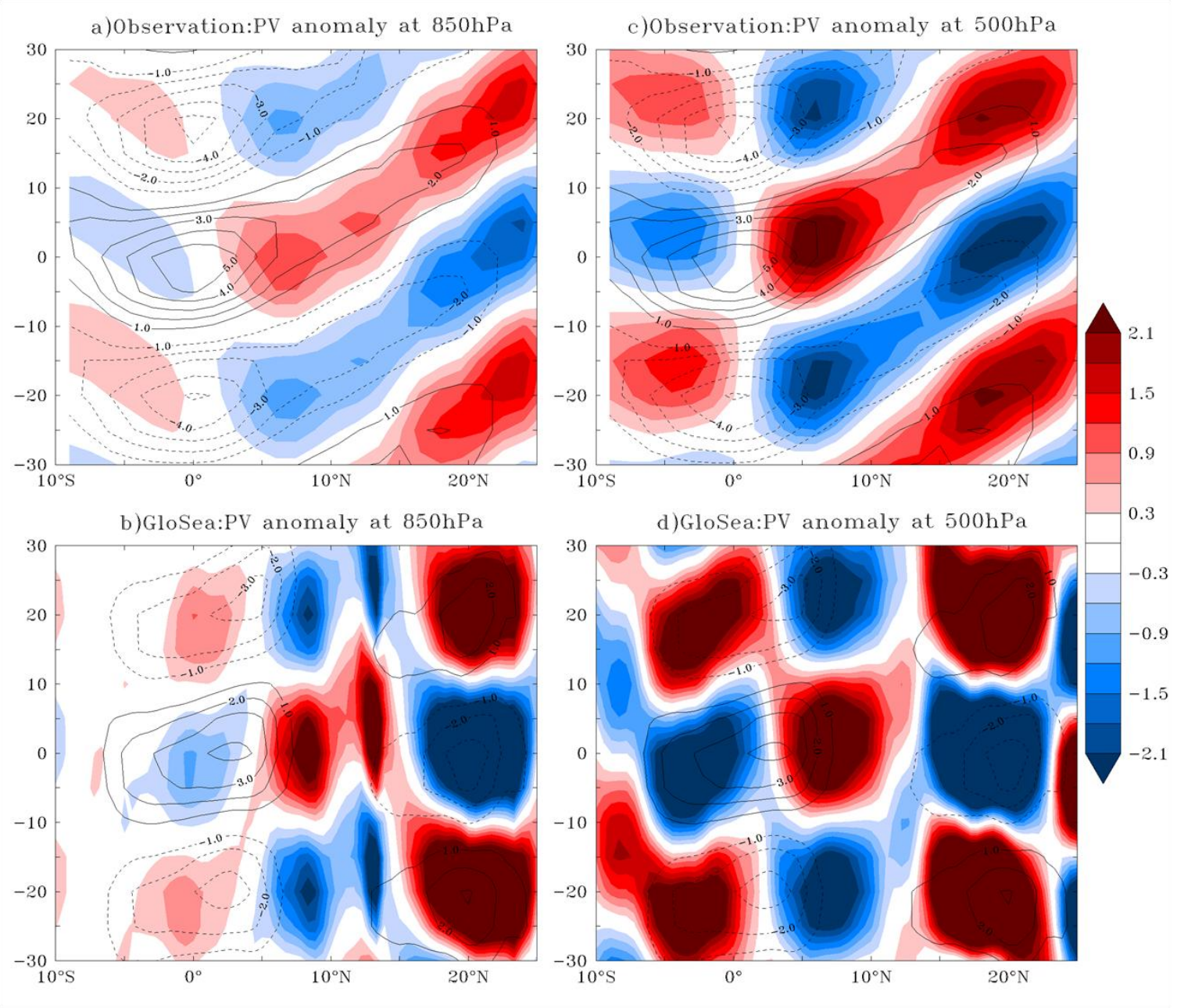

792 Fig.14 Lag regression of $850 \mathrm{hPa} \mathrm{PV}\left(\mathrm{x} 10^{2} \mathrm{PVU}, 1 \mathrm{PVU}=10^{-6} \mathrm{~K} \mathrm{~m}^{2} \mathrm{Kg}^{-1} \mathrm{~s}^{1}\right.$, shaded) and 793 precipitation anomalies (contours) onto normalized precipitation anomalies in the central 794 equatorial Indian Ocean region $\left(70^{\circ}-95^{\circ} \mathrm{E}, 5^{\circ} \mathrm{S}-5^{\circ} \mathrm{N}\right)$ from ERA-Interim (a) and GloSea5 (b). (c,d) 795 Same as $(\mathrm{a}, \mathrm{b})$ but for $500 \mathrm{hPa} \mathrm{PV}$ anomalies. 
800 


\begin{tabular}{|c|c|c|c|c|c|c|c|c|c|c|c|c|c|c|c|c|c|c|c|c|}
\hline \multirow{3}{*}{ year } & \multirow{2}{*}{\multicolumn{2}{|c|}{ TRMM }} & \multicolumn{6}{|c|}{ ENSEMBLE-1 } & \multicolumn{6}{|c|}{ ENSEMBLE-2 } & \multicolumn{6}{|c|}{ ENSEMBLE-3 } \\
\hline & & & \multicolumn{2}{|c|}{ April 25} & \multicolumn{2}{|c|}{ May 5} & \multicolumn{2}{|l|}{ May 9} & \multicolumn{2}{|c|}{ April 25} & \multicolumn{2}{|c|}{ May 5} & \multicolumn{2}{|l|}{ May 9} & \multicolumn{2}{|c|}{ April 25} & \multicolumn{2}{|c|}{ May 5} & \multicolumn{2}{|l|}{ May 9} \\
\hline & Active & Break & Active & Break & Active & Break & Active & Break & Active & Break & Active & Break & Active & Break & Active & Break & Active & Break & Active & Break \\
\hline 1996 & & & $\begin{array}{l}1-3 \mathrm{~J}, \\
10-13 \mathrm{~J} \\
, 20-23 \mathrm{~J}\end{array}$ & $\begin{array}{l}3-14 \mathrm{~J}, \\
22-25 \mathrm{~J}\end{array}$ & $\begin{array}{l}22-24 J \\
7-10 A \\
18-20 A\end{array}$ & $\begin{array}{l}12- \\
21 \mathrm{~J}, 4- \\
10 \mathrm{~A}, \\
14-21 \mathrm{~A}\end{array}$ & $\begin{array}{l}\text { 15-18J, } \\
\text { 22-25J }\end{array}$ & 13-15A & & & $2-4 J$ & $\begin{array}{l}\text { 30J- } \\
\text { 3A }\end{array}$ & $\begin{array}{l}2-4 \mathrm{~J}, 10- \\
12 \mathrm{~J}, 15- \\
19 \mathrm{~J}, \\
31 \mathrm{~J}, \\
1 \mathrm{~A},-12 \mathrm{~A}\end{array}$ & $20-22 \mathrm{~A}$ & 19-23J & & 15-18J & $\begin{array}{l}15- \\
21 \mathrm{~J}, 4- \\
10 \mathrm{~A}, \\
14-21 \mathrm{~A}\end{array}$ & $\begin{array}{l}2-6 \mathrm{~J}, \\
17-19 \mathrm{~J}\end{array}$ & \\
\hline 1997 & & & $\begin{array}{l}12- \\
14 \mathrm{~A} \\
26-28 \mathrm{~A}\end{array}$ & $20-22 A$ & & 1-11J & & 6-15J & 2-8J & $\begin{array}{l}10- \\
12 \mathrm{~A}, 16 \\
-19 \mathrm{~A}\end{array}$ & $21-24 A$ & $\begin{array}{l}23- \\
\text { 31J }\end{array}$ & & $\begin{array}{l}2-15 \mathrm{~J}, 7- \\
11 \mathrm{~A}\end{array}$ & $\begin{array}{l}19- \\
21 \mathrm{~A}, \\
27-31 \mathrm{~A}\end{array}$ & $7-17 \mathrm{~J}$ & & $5-12 J$ & & $\begin{array}{l}5-6 \mathrm{~J}, \\
10-18 \mathrm{~J}, \\
14- \\
18 \mathrm{~A}, \\
21-24 \mathrm{~A}\end{array}$ \\
\hline 1998 & $2-5 \mathrm{~J}$ & $\begin{array}{l}18-26 \mathrm{~J} \\
, 4-6 \mathrm{~A} \\
17-19 \mathrm{~A}\end{array}$ & $\begin{array}{l}\text { 13-16J, } \\
24- \\
\text { 27J,7- } \\
\text { 9A }\end{array}$ & 26-29J & $\begin{array}{l}\text { 13-17J, } \\
22-24 \mathrm{~A}\end{array}$ & & $\begin{array}{l}\text { 10-13J, } \\
\text { 6-8A }\end{array}$ & 1-6J & 5-7A & & $20-24 \mathrm{~A}$ & $\begin{array}{l}13- \\
15 \mathrm{~J}, 2 \\
0- \\
29 \mathrm{~J}, 1 \\
3-15 \mathrm{~A}\end{array}$ & 26-28J, & $\begin{array}{l}2-7 \mathrm{~J}, 11- \\
13 \mathrm{~A}\end{array}$ & $17-22 \mathrm{~J}$ & 15-19J & $\begin{array}{l}13-17 J \\
22-24 \mathrm{~A}\end{array}$ & & $\begin{array}{l}3-4 \mathrm{~J}, \\
31 \mathrm{~J}-2 \mathrm{~A}\end{array}$ & $\begin{array}{l}18-21 \mathrm{~J}, \\
28-30 \mathrm{~A}\end{array}$ \\
\hline 1999 & $9-14 \mathrm{~A}$ & $\begin{array}{l}1-5 \mathrm{~J}, \\
29-31 \mathrm{~J} . \\
10-15 \mathrm{~A}\end{array}$ & & $\begin{array}{l}\text { 8-12J, } \\
\text { 9-12A }\end{array}$ & $\begin{array}{l}\text { 6-9J, } \\
\text { 6-9A }\end{array}$ & $29 \mathrm{~J}-2 \mathrm{~A}$ & 14-16J, & & $\begin{array}{l}2-4 \mathrm{~J}, \\
17-23 \mathrm{~A}\end{array}$ & 6-10A & & $\begin{array}{l}21 \mathrm{~J}- \\
2 \mathrm{~A}, 7- \\
10 \mathrm{~A}\end{array}$ & $\begin{array}{l}\text { 3-10J, } \\
\text { 21-24J }\end{array}$ & & $\begin{array}{l}\text { 4-9J, } \\
\text { 5-11A }\end{array}$ & $12-20 A$ & $\begin{array}{l}\text { 6-9J, } \\
\text { 6-9A }\end{array}$ & 9-14A & & \\
\hline 2000 & $\begin{array}{l}6- \\
13 \mathrm{~A}, 17 \\
-19 \mathrm{~A}\end{array}$ & $\begin{array}{l}21 \mathrm{~J}- \\
6 \mathrm{~A}, 1- \\
6 \mathrm{~A}, 19- \\
21 \mathrm{~A}\end{array}$ & $\begin{array}{l}27- \\
29 \mathrm{~J}, 4- \\
6 \mathrm{~A}, 18- \\
22 \mathrm{~A}\end{array}$ & $\begin{array}{l}6-16 \mathrm{~J}, \\
30-31 \mathrm{~J}, \\
1-3 \mathrm{~A}\end{array}$ & $\begin{array}{l}13- \\
15 A \\
21-23 A\end{array}$ & 7-9J & $\begin{array}{l}\text { 9-11J, } \\
\text { 28-30J, } \\
\text { 17-19A }\end{array}$ & & $\begin{array}{l}3- \\
8 \mathrm{~A}, 16- \\
19 \mathrm{~A}\end{array}$ & & $8-14 A$ & $\begin{array}{l}\text { 21- } \\
\text { 23J }\end{array}$ & $\begin{array}{l}\text { 23-25J, } \\
17-20 \mathrm{~A}\end{array}$ & $\begin{array}{l}\text { 1-4J, } \\
25 \mathrm{~J}-2 \mathrm{~A}\end{array}$ & $8-22 \mathrm{~A}$ & $\begin{array}{l}\text { 7-19J, } \\
\text { 29-3A }\end{array}$ & $\begin{array}{l}13- \\
15 \mathrm{~A} \\
21-23 \mathrm{~A}\end{array}$ & $8-12 J$ & $\begin{array}{l}5-7 \mathrm{~J}, \\
12-14 \mathrm{~J}\end{array}$ & $\begin{array}{l}\text { 25-28J, } \\
11-13 \mathrm{~A}\end{array}$ \\
\hline 2001 & $7-11 \mathrm{~J}$ & $\begin{array}{l}24 \mathrm{~J}- \\
1 \mathrm{~A}, 25- \\
29 \mathrm{~A}\end{array}$ & $25-27 \mathbf{J}$ & $3-5 \mathrm{~A}$ & $18-20 \mathrm{~J}$ & 3-8A & $\begin{array}{l}3-5 \mathrm{~J}, 20- \\
22 \mathrm{~J}, 14- \\
16 \mathrm{~A}\end{array}$ & & $\begin{array}{l}26- \\
28 J, 1- \\
6 A, 13- \\
16 A, 19 \\
-22 A\end{array}$ & & $\begin{array}{l}10- \\
12 \mathrm{~J}, 23- \\
26 \mathrm{~J}, 21- \\
24 \mathrm{~A}\end{array}$ & & & $26-30 \mathrm{~J}$ & 26-29J & 23-27A & 18-20J & 23-26A & 21-23J, & 9-18J \\
\hline
\end{tabular}




\begin{tabular}{|c|c|c|c|c|c|c|c|c|c|c|c|c|c|c|c|c|c|c|c|c|}
\hline 2002 & $22-24 A$ & $\begin{array}{l}1-13 \mathrm{~J} \\
, 21- \\
29 \mathrm{~J}, \\
19-21 \mathrm{~A}\end{array}$ & $\begin{array}{l}2-5 \mathrm{~J}, 9- \\
12 \mathrm{~J}, \\
29 \mathrm{~J}-1 \mathrm{~A}\end{array}$ & $1-6 \mathrm{~J}$ & $\begin{array}{l}\text { 8-10J, } \\
21-23 J\end{array}$ & & & & $\begin{array}{l}8- \\
10 \mathrm{~A}, 13 \\
-20 \mathrm{~A}\end{array}$ & $17-23 J$ & $\begin{array}{l}8-10 J \\
21-23 J\end{array}$ & & & $\begin{array}{l}14-21 \mathrm{~J}, \\
24-27 \mathrm{~J}, \\
10-12 \mathrm{~A}, \\
16-29 \mathrm{~A}\end{array}$ & $\begin{array}{l}\text { 4-10J, } \\
27-29 J\end{array}$ & 20-29J & $\begin{array}{l}8-10 J \\
21-23 J\end{array}$ & $12-15 J$ & $\begin{array}{l}10- \\
14 A, \\
24-26 A\end{array}$ & 9-11J \\
\hline 2003 & $\begin{array}{l}23-27 J \\
, 22- \\
24 A\end{array}$ & 29J-1A & $\begin{array}{l}4-6 \mathrm{~J}, \\
29-31 \mathrm{~J}\end{array}$ & & $\begin{array}{l}2-4 J, \\
11- \\
16 J, 8- \\
10 A, \\
21-24 A\end{array}$ & & $\begin{array}{l}1-3 J, 13- \\
15 A, 22- \\
26 A\end{array}$ & $\begin{array}{l}22-31 \mathrm{~J}, \\
1-4 \mathrm{~A}\end{array}$ & $20-22 A$ & $18-20 A$ & $\begin{array}{l}2-4 \mathrm{~J}, \\
11- \\
16 \mathrm{~J}, 8- \\
10 \mathrm{~A}, \\
21-24 \mathrm{~A}\end{array}$ & $\begin{array}{l}11- \\
14 \mathrm{~J}, 2 \\
6-28 \mathrm{~J}\end{array}$ & $\begin{array}{l}\text { 6-9J, 21- } \\
23 \mathrm{~A}\end{array}$ & $16-18 J$ & $\begin{array}{l}24- \\
29 J\end{array}$ & & $\begin{array}{l}2-4 \mathrm{~J}, \\
11- \\
16 \mathrm{~J}, 8- \\
10 \mathrm{~A}, \\
21-24 \mathrm{~A}\end{array}$ & $27 \mathrm{~J}-5 \mathrm{~A}$ & $\begin{array}{l}2-14 J \\
20-22 J\end{array}$ & 5-7A \\
\hline 2004 & $\begin{array}{l}3-8 A, \\
20-22 A\end{array}$ & $\begin{array}{l}\text { 8-12J, } \\
24-31 A\end{array}$ & & & $2-5 A$ & & & $1-8 \mathrm{~J}$ & $\begin{array}{l}8-11 J, \\
21- \\
24 J, 19- \\
21 A\end{array}$ & $18-20 A$ & $\begin{array}{l}5- \\
8 J, 13- \\
15 J, \\
27- \\
29 A, 8- \\
10 A, 21 \\
-24 A\end{array}$ & & $\begin{array}{l}19-22 J \\
14-16 A \\
22-24 A\end{array}$ & $1-6 J$ & & 21-30A & $2-5 A$ & & & $1-3 J$ \\
\hline 2005 & 24J-1A & $\begin{array}{l}16-18 J, \\
7-13 A, \\
23-31 A\end{array}$ & $\begin{array}{l}14-17 \mathrm{~J}, \\
29 \mathrm{~J}- \\
1 \mathrm{~A}, 6- \\
13 \mathrm{~A}, \\
24-27 \mathrm{~A}\end{array}$ & & $\begin{array}{l}17-21 \mathrm{~J}, \\
16-18 \mathrm{~A}\end{array}$ & & 3-6A & $\begin{array}{l}6-15 \mathrm{~J} \\
20-28 \mathrm{~A}\end{array}$ & $\begin{array}{l}3-5 J, 2- \\
4 A, 12- \\
14 A\end{array}$ & $\begin{array}{l}28- \\
30 J, 3- \\
7 A\end{array}$ & $\begin{array}{l}8- \\
12 J, 15- \\
17 \mathrm{~A}, 21 \\
-23 A\end{array}$ & $\begin{array}{l}17- \\
28 J\end{array}$ & $\begin{array}{l}4-7 J, 11- \\
17 J, 23- \\
26 J\end{array}$ & $\begin{array}{l}\text { 14-18A, } \\
21-23 A\end{array}$ & $\begin{array}{l}16- \\
22 J, \\
29 J-6 A\end{array}$ & & $\begin{array}{l}17-21 \mathrm{~J}, \\
16-18 \mathrm{~A}\end{array}$ & & $\begin{array}{l}\text { 30-31J, } \\
\text { 1A }\end{array}$ & \\
\hline 2006 & $\begin{array}{l}1-5 \mathrm{~J}, \\
20 \mathrm{~J}-1 \mathrm{~A} \\
, 4-7 \mathrm{~A}, \\
11-19 \mathrm{~A} \\
\text {,29- } \\
31 \mathrm{~A}\end{array}$ & $\begin{array}{l}10-13 J, \\
23-25 J, \\
24-27 \text { A }\end{array}$ & $\begin{array}{l}1-5 \mathrm{~J}, 7- \\
10 \mathrm{~J}\end{array}$ & $\begin{array}{l}1-4 \mathrm{~J}, \\
23-30 \mathrm{~J}, \\
7-9 \mathrm{~A}, \\
17-19 A\end{array}$ & $\begin{array}{l}13-15 J, \\
25-28 J, \\
3-5 A\end{array}$ & $2-4 \mathrm{~J}$ & 15-18J & 1-8J & $\begin{array}{l}2-4 J, 8- \\
11 \mathrm{~J}, 3- \\
5 \mathrm{~A}\end{array}$ & $\begin{array}{l}23- \\
28 J, 14- \\
18 A\end{array}$ & $\begin{array}{l}2- \\
6 \mathrm{~J}, 29 \mathrm{~J}- \\
2 \mathrm{~A}\end{array}$ & & $\begin{array}{l}\text { 21-30J,6- } \\
\text { 9A }\end{array}$ & $2-11 J$ & $\begin{array}{l}8- \\
12 J, 5- \\
11 \mathrm{~A}\end{array}$ & $\begin{array}{l}5-12 J, \\
15- \\
19 A,\end{array}$ & $\begin{array}{l}13-15 \mathrm{~J}, \\
25-28 \mathrm{~J}, \\
3-5 \mathrm{~A}\end{array}$ & 7-9J & 28-30J & $\begin{array}{l}16-19 J, \\
14-17 A\end{array}$ \\
\hline 2007 & $\begin{array}{l}1-8 J \\
, 4-8 A \\
, 26- \\
28 A\end{array}$ & $\begin{array}{l}17- \\
24 J, 14- \\
16 A\end{array}$ & $\begin{array}{l}3-7 \mathrm{~J}, \\
20-23, \\
\mathrm{~J}, \quad 25- \\
28 \mathrm{~A}\end{array}$ & $16-21 \mathrm{~A}$ & $\begin{array}{l}22-25 \mathrm{~J} \\
15-7 \mathrm{~A}, \\
21-23 \mathrm{~A}\end{array}$ & $11-13 \mathrm{~J}$ & $\begin{array}{l}1-16 \mathrm{~J} \\
23-28 \mathrm{~A}\end{array}$ & $1-12 A$ & $\begin{array}{l}28- \\
30 J, 17- \\
19 A\end{array}$ & & 13-15J & & 23-25J, & & $\begin{array}{l}6-13 J, \\
21-25, \\
J,\end{array}$ & & $\begin{array}{l}22-25 J \\
15-7 A, \\
21-23 A\end{array}$ & $15-22 \mathrm{~J}$ & 29-31J & 23-26J \\
\hline 2008 & $\begin{array}{l}27-29 J \\
, 9-12 A\end{array}$ & $\begin{array}{l}12- \\
20 J, 20- \\
23 A\end{array}$ & $\begin{array}{l}8-10 J, \\
18-21 J\end{array}$ & 4-12J & $\begin{array}{l}\text { 7-9J, } \\
\text { 24-31J }\end{array}$ & 11-13J & $25-27 A$ & $\begin{array}{l}4-9 A, \\
8-12 A\end{array}$ & 21-27J & $2-6 J$ & $\begin{array}{l}22- \\
26 J, 13- \\
16 A\end{array}$ & & $\begin{array}{ll}2-6 \mathrm{~J}, & 14- \\
16 \mathrm{~J}, & 12- \\
14 \mathrm{~A}, & 19- \\
21 \mathrm{~A} & \end{array}$ & 6-9A & 10-13J & $4-8 A$ & $\begin{array}{l}7-9 J, \\
24-31 J\end{array}$ & $18-25 J$ & 23-25J & $5-16 A$ \\
\hline 2009 & $\begin{array}{l}5-7 \mathrm{~J}, \\
12- \\
15 \mathrm{~J}, 18- \\
22 \mathrm{~J}, 25-\end{array}$ & $\begin{array}{l}24 J- \\
9 A, 15- \\
18 A\end{array}$ & $\begin{array}{l}3-5 \mathrm{~J}, \\
22-25 \mathrm{~J}, \\
31 \mathrm{~J}-2 \mathrm{~A}\end{array}$ & $12-21 J$ & $\begin{array}{l}22-29 J \\
4-10 A, \\
14-21 A\end{array}$ & 6-16J & $\begin{array}{l}7-11 \mathrm{~J}, \\
12-14 \mathrm{~A}\end{array}$ & $24-26 J$ & $5-8 J$ & $30 \mathrm{~J}-6 \mathrm{~A}$ & $\begin{array}{l}16- \\
21 J, 17- \\
19 A\end{array}$ & & $8-16 A$ & 3-10J & $\begin{array}{l}5-8 J, \\
21- \\
26 J, 2-\end{array}$ & 27-31J & $\begin{array}{l}22-29 J \\
13-20 A\end{array}$ & 1-9J & $15-21 \mathrm{~A}$ & $\begin{array}{l}2-8 J, \\
15-17 J, \\
24-31 J,\end{array}$ \\
\hline
\end{tabular}




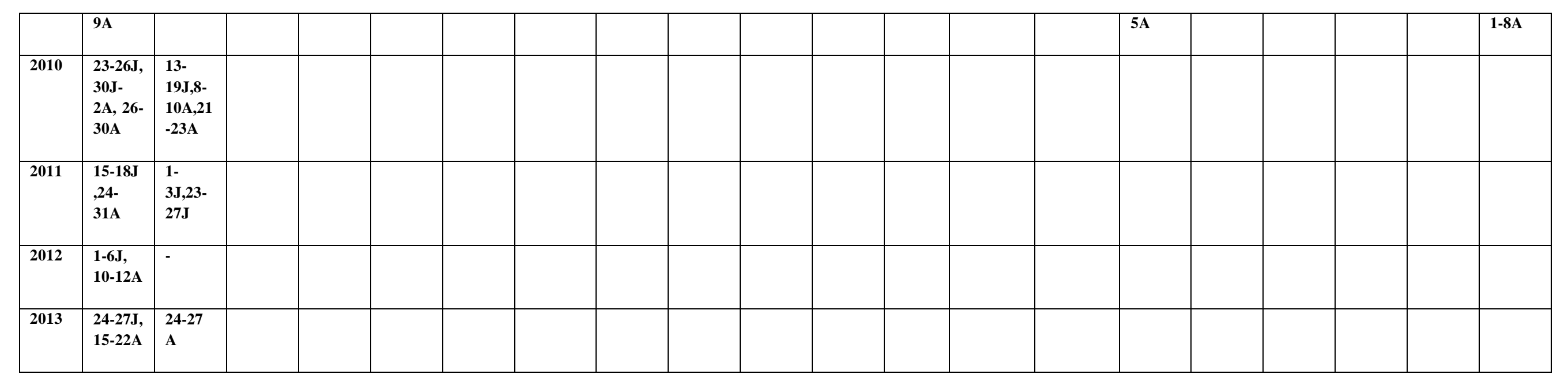

Table 1 List of active and break events based on the TRMM rainfall index from the MCZ region (see text for details) for the July-August period of 1998-2013 (columns 2-3). The same approach is used for selecting active-break events from three hindcast members of GloSea5, denoted ENSEMBLE-1, ENSEMBLE2 and ENSEMBLE3 generated using stochastic perturbed physics and with three initial condition dates April 25, May 5 and May 9 for the period of 1996-2009. Letters ' $\mathbf{J}$ ' and 'A' denote July and August. Note that we would not expect the dates of events in GloSea5 to match those in observations due to the length of time elapsed in July/August since the initialization of the seasonal forecasts. 